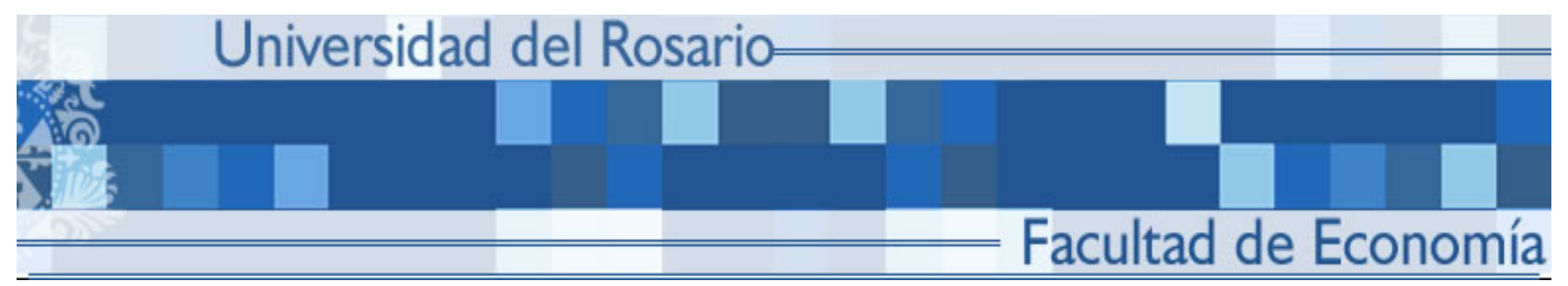

\title{
DOES THE UNEMPLOYMENT BENEFIT INSTITUTION AFFECT THE PRODUCTIVITY OF WORKERS? EVIDENCE FROM A FIELD EXPERIMENT
}

Mariana Blanco

Patricio S. Dalton

Juan F. Vargas

\section{SERIE DOCUMENTOS DE TRABAJ O}

No. 145

Noviembre de 2013 


\title{
Does the Unemployment Benefit Institution affect the Productivity of Workers? Evidence from a Field Experiment*
}

\author{
Mariana Blanco $^{\dagger} \quad$ Patricio S. Dalton ${ }^{\ddagger} \quad$ Juan F. Vargas $^{\dagger}$
}

November 4, 2013

\begin{abstract}
We investigate whether and how the type of unemployment benefit institution affects productivity. We designed a field experiment to compare workers' productivity under a welfare system, where the unemployed receive an unconditional monetary transfer, with their productivity under a workfare system, where the transfer is received conditional on the unemployed spending some time on ancillary activities. First, we find that having an unemployment benefit institution, regardless of whether it makes transfers conditional or unconditional, increases workers' productivity. Second, we find that productivity is higher under Welfare than under Workfare. Becoming unemployed under Welfare comes at the psychological cost of a drop in self-esteem, presumably due to the shame or stigma associated with receiving an unconditional unemployment benefit. We document the empirical relevance of precisely this channel. The differences we observe in productivity suggest that this psychological cost acts as an extra nonmonetary incentive for workers under Welfare to put a higher effort in their work.
\end{abstract}

JEL: J24, J65, J45

Keywords: Unemployment Benefits, Workfare, Productivity, Self-esteem, Shame.

${ }^{*}$ We are grateful to Lina Díaz for excellent research assistance and field work leadership. We also thank the assistance in the field of Darío Romero, Viviana Garcia, Julián Hidalgo, Laura Hincapié, Natalia Lemus, Carlos Salamanca, Diana Salazar and Mauricio Vela. We thank Ximena Cadena, Juan C. Cárdenas, Leopoldo Fergusson and Ana M. Ibáñez for support with the logistics of the experiment in Universidad de Los Andes. We are grateful to Dan Houser, Tobias Klein, Steven Poelhekke, to participants at the 2012 International ESA Conference, the 4th Development Economics Workshop at Tilburg, the 2013 Florence Workshop on Behavioral and Experimental Economics, the 6th Maastricht Behavioral and Experimental Economics Symposium, the WZB Conference on Fertile Fields in Development, the Monash-Warwick Workshop in Development Economics and the economic seminars at Tilburg, Universidad del Rosario, Universidad de Los Andes and Universidad de Buenos Aires for useful comments and suggestions. Financial support from Universidad del Rosario is gratefully acknowledged.

${ }^{\dagger}$ Universidad del Rosario, Facultad de Economía, Cl 12c No 4 - 69 Bogotá, Colombia. E-mails: mariana.blanco@urosario.edu.co and juan.vargas@urosario.edu.co.

${ }^{\ddagger}$ Tilburg University, Economics Department, CentER and CAGE, Warandelaan 2, 5037 AB, Tilburg, The Netherlands. E-mail: p.s.dalton@uvt.nl. 


\section{Introduction}

This paper uses data from a field-experiment designed to investigate whether the type of unemployment benefit system affects the productivity of workers. According to the International Labour Organization (ILO), $42 \%$ of the countries worldwide have some type of statutory unemployment benefit institution (hereafter UBI) that provides a safety net for the households and acts as an automatic stabilizer of the economy (ILO, 2010). Some countries, like most Western European nations and developing countries like Colombia, implement the so called "welfare" scheme, which consists of an unconditional cash transfer to the unemployed. Others like Argentina, Australia and Brazil, implement the so called "workfare" scheme instead, which consists on monetary transfers to the unemployed conditional on the recipient performing some kind of work in return. Yet, a third set of countries like the US, the UK and Chile offer both "welfare" and "workfare"-type programs. ${ }^{1}$

Despite being widely implemented worldwide, little is known about the impact of these institutions on the economy. ${ }^{2}$ For instance, one relevant concern, that has however been largely understudied, is the effect of these institutions on workers' productivity. From a purely economic point of view, one would expect productivity of workers under welfare UBIs to be the lowest, simply because an unconditional unemployment benefit should make the cost of being unemployed lower than under workfare UBIs, and also lower than under no UBI. However, this argument overlooks the effects of unemployment on the psychological well-being of the unemployed (see Darity and Goldsmith, 1996, for a review), which may differ across UBIs. Once we allow for the psychological aspects to affect the cost of unemployment, this prediction becomes less clear.

Investigating these questions using observational data is challenging for several reasons. To name only a few, the implementation of different UBIs is likely to be correlated with country-specific institutional characteristics that may affect workers' productivity through other channels. Moreover, obtaining independent and objective measures of individual-level productivity is a difficult task, as it is finding the right counterfactual for assessing how these measures are affected by the specific UBI in place. For these reasons, we designed a novel field-experiment that allowed us to study this matter. In a nutshell, we created employment and unemployment in the field. We recorded daily measures of workers' productivity under different UBIs and collected psychological traits of employed and unemployed workers before and during the project.

We hired over 300 students from two major private Universities in Bogotá, Colombia

\footnotetext{
${ }^{1}$ See Ochel (2005) for a survey on workfare programs and Gueron (1990) for a discussion on the two types of schemes.

${ }^{2}$ There is work on the effect of different variations of welfare schemes (e.g. different sizes of the monetary benefit, different application requirements, different maturities of the benefit) on unemployment duration, search effort, and reservation wages (e.g. Abbrig et al., 2005, Boone et al., 2007). However, to our knowledge, there is no empirical evidence comparing the effects of welfare versus workfare schemes, or versus a situation without unemployment benefits.
} 
(University of Rosario and University of Los Andes), to work as research assistants for a one-month period. Their job was to code into a computer spreadsheet news on local politicians taken from the online archives of Colombian newspapers. Individual productivity was measured by counting the number of news correctly codified. Before starting the job, students were informed that the demand for coders would vary from day to day. Some days there would be a shortage of vacancies and those with lower productivity would become temporarily unemployed. Some other days there would be an increase in the demand for coding allowing some of the unemployed to return to work.

The experiment was implemented in two separate stages, with the task described being the same in both. In one stage, we ran simultaneously two identical Control interventions in each university. This constituted the benchmark of our analysis and resembled a system in which no UBI is in place. Indeed, the unemployed in this stage received no monetary compensation, independent of their university. In another stage each university was assigned to one UBI, with all the employees within each university receiving the same treatment. We chose this design to avoid the type of spillovers and contamination that would arise if peers or classmates from the same university were hired to do the same job under different working conditions. ${ }^{3}$ Students employed in U. Rosario were assigned to a Welfare UBI treatment, and hence if became unemployed were given an unconditional monetary compensation, equivalent to $30 \%$ of the daily salary of their employed peers. Students employed in U. Andes were assigned to a Workfare UBI treatment, and hence the unemployed received an equivalent (30\% of daily salary) compensation in exchange for spending 30 minutes (one third of a coding shift) doing an administrative task. ${ }^{4}$

To identify the effect of the different UBIs on the productivity of workers, we use a difference-in-differences specification to compare the productivity differential of the two groups based in U. Rosario (Welfare and Control) with the differential productivity of the two groups based in U. Andes (Workfare and Control). We find that the UBI-affected workers are more productive than their Control peers in both cases, which suggests that both Workfare and Welfare generate productivity gains compared to the baseline without any UBI. Most importantly, the productivity gain of the Welfare employees more than doubles that of their Workfare counterparts, which suggests that the utility loss of being unemployed is higher under Welfare, even in the absence of any task that entails a costly effort.

This result seems to be at odds with the conventional economics perspective. Because effort is costly, when facing the possibility of being laid off people should try to avoid unemployment more under a workfare-type UBI than under a welfare one. Hence, we

\footnotetext{
${ }^{3}$ We explain our design with further detail in Section 3.

${ }^{4}$ We could have also considered a training-type UBI in which the monetary compensation is received upon participation in a training program. However, we did not implemented this type of scheme because we wanted to focus on the most used systems worldwide, i.e. welfare and workfare. Considering a training-type UBI is interesting on its own, but it is beyond the scope of this paper.
} 
investigate potential non-economic mechanisms that may drive our results. Notably, we observe a significant drop in the self-esteem of workers who become unemployed under the Welfare treatment, suggesting that being offered a monetary benefit while unemployed and idle comes at a psychological cost. According to the psychology literature this cost could be associated with shame or stigma. Importantly, we do not observe a differential drop in selfesteem of the unemployed workers under Workfare or in the Control treatment, suggesting that the psychological cost is not a consequence of just being unemployed, but rather of being unemployed and being offered money in exchange of nothing. It is the combination of these two factors what seems to be triggering the observable psychological cost.

We explore potential heterogeneous effects across different types of workers. We find that the biggest proportion of the productivity differences across treatments is explained by workers who never experienced unemployment during the duration of the project. This suggests that workers under Welfare anticipate this psychological cost, and react by putting higher effort and being more productive than workers under the other schemes. This result is in line with the recent literature on ego utility, where people take costly actions to protect their self-esteem (see Köszegi, 2006). ${ }^{5}$

We investigate alternative mechanisms that could also explain our results, like employees' reciprocity towards the employers, but we find no evidence in their favor, providing further support to our interpretation.

Our paper contributes to several strands of the literature. First, while the literature on incentives and workers' productivity studies the effect of incentive schemes provided within the working place (like different types of compensation, Prendergast 1999), we show how productivity responds to (economic and psychological) incentives provided outside the working place. Second, we contribute to the literature on the labor market consequences of unemployment benefits (see Fredriksson and Holmlund, 2006 for a recent review). For instance, we complement Acemoglu and Shimer (2000), who study how UBIs affect ex-ante productivity by determining the type of jobs the unemployed apply to. In contrast, we show how UBIs affect productivity ex-post, once the job has been chosen. ${ }^{6}$ Third, by showing how the UBI interacts with the psychological impact of unemployment on self-esteem, the paper contributes to the literature on the psychological effects of unemployment. We show that unemployment affects self-esteem only when the unemployed receive an unconditional monetary compensation. Finally, from a methodological point of view, this paper illustrates how observational data in labor economics can be complemented with data gathered from field experiments for the purpose of studying labor market institutions and outcomes. The closest related paper in this respect is Black et al. (2003), who use random assignment

\footnotetext{
${ }^{5}$ See also De Hooge, Breugelmans and Zeelenberg (2008) for evidence on shame avoidance as motivator of behavior.

${ }^{6}$ Besley and Coate (1992) develop a theoretical model to compare welfare versus workfare-type schemes. Their focus is however different from ours, as they study the optimal design of workfare programs considering that work requirements may serve as screening and deterrence devices.
} 
to the unemployment insurance system to show that the threat of being forced to take up reemployment training services reduces the duration of the benefit. In contrast, we do not look at training for reemployment but instead we look at the work requirement to receive the benefit, and focus on productivity as outcome instead of the duration of unemployment. Falk, et al. (2006) run a laboratory experiment on the effect of UBIs on labor supply. In the experiment, the job of 'employees' is counting the number of zeros in a zeroes-and-ones matrix printed on a sheet of paper. An important feature of our design is that we are able to precisely measure workers' productivity without departing from a natural job setting. Their study, which suggests a positive effect of a workfare-type UBI on labor supply, does not look at the effect on productivity.

The rest of the paper is organized as follows. Section 2 presents a simple conceptual economic framework that illustrates how the different UBIs should affect workers productivity under standard economic assumptions. Section 3 introduces the experimental design. Section 4 describes the characteristics of the sample and the data collected in the experiment. Section 5 presents the empirical results and Section 6 studies the underlying mechanism behind the main result and revisits the economic framework of Section 2. Finally, Section 7 concludes.

\section{Conceptual Framework}

In this Section, we present a simple framework that allows us to derive basic hypotheses on how the UBI influences workers' effort and hence their productivity. We will use this framework as the economic benchmark to contrast our results with. Hence, at this point we only use standard economic assumptions.

In our experiment, workers receive a fix wage independent of their effort, so in principle, they would have incentives to shirk. However, the possibility of being laid off depends on workers' relative productivity (i.e. workers' relative effort), which counterbalances these incentives. Unemployment then acts as a discipline device for workers as in Shapiro and Stiglitz (1984), and the incentive to shirk will depend on the costs and benefits of unemployment. $^{7}$ The key characteristic of the model we introduce here is that these costs and benefits will differ across the three interventions considered in our experiment. In other words, workers' incentives to shirk depend only on the unemployment benefit system they are assigned to in the experiment. ${ }^{8}$

\footnotetext{
${ }^{7}$ In a framework without unemployment there would be no penalty for shirking so workers would always choose to shirk.

${ }^{8}$ Although our setting shares similar features with Shapiro and Stiglitz (1984), it is essentially different in that we exogenously impose the unemployment rate, the unemployment benefit and the wage. For that reason, we do not need to model the decision of the employer (wages are set exogenously in our experiment) and we only focus on the decision of the employee to exert effort while employed.
} 


\section{$2.1 \quad$ Set up}

Consider a fixed number, $N$, of identical workers, all of whom obtain utility from consumption and disutility from exerting effort. We assume for simplicity that the utility function of the representative worker is separable and that workers are risk neutral. Thus, we can write the instantaneous utility function of a worker as $U(w, e)=w-e$, where $w$ is the wage received and $e$ is the level of effort exerted on his job. Let us further assume, also for simplicity, that workers can provide either minimal effort $(e=0)$, or some fixed positive level, $e>0 .{ }^{9}$ Each worker is in one of two states at any point in time: employed or unemployed.

When employed, the worker has to choose an effort level $e$. If the worker does not shirk, he receives a wage of $w$ and looses his job with probability $b$. If a worker shirks, he looses his job with probability $q .{ }^{10}$ The worker selects an effort level to maximize his expected present discounted value of utility with a discount rate $r>0$. This involves comparing the expected lifetime utility of a non-shirker employed, $V_{E}^{N}$, with the expected lifetime utility of an unemployed worker, $V_{U}$. Shapiro and Stiglitz's (1984)'s "fundamental asset equation" for an employed shirker is:

$$
r V_{E}^{S}=w+(b+q)\left(V_{U}-V_{E}^{S}\right)
$$

$V_{E}^{S}$ represents the "asset value", $w$ is the "flow benefit" and the expected "capital gain" (actually a loss) is the probability of job loss for a shirker $(b+q)$ times the amount of utility lost by becoming unemployed $\left(V_{U}-V_{E}^{S}\right)$. The real interest rate and utility discount rate are both equal to the constant $r$. Likewise, the "fundamental asset equation" for an employed non-shirker is:

$$
r V_{E}^{N}=w-e+b\left(V_{U}-V_{E}^{N}\right)
$$

Solving equations (1) and (2) for $V_{E}^{S}$ and $V_{E}^{N}$ yields:

$$
\begin{aligned}
& V_{E}^{S}=\frac{w+(b+q) V_{U}}{r+b+q} \\
& V_{E}^{N}=\frac{(w-e)+b V_{U}}{r+b}
\end{aligned}
$$

\footnotetext{
${ }^{9}$ We make this assumption in order to keep our framework as close as possible to Shapiro and Stiglitz (1984)'s seminal model. However we note that, including effort as a continuous variable would not change the qualitative results.

${ }^{10}$ Both $b$ and $q$ are assumed to be exogenous to the worker. In our experiment, however, both are decreasing in worker's relative performance and increasing in the unemployment rate of the following day. None of these factors are known to the worker. Arguably, workers may have prior beliefs about their relative performance and they could in principle update their beliefs during the period of the project. Introducing this to the model, however, would only complicate the set up without adding anything essential. Recall that our main aim is to compare behavior across treatments, and insofar as learning of these parameters is not significantly different across treatments, treating $b$ and $q$ as exogenous parameters in our model does not come at any cost.
} 
The worker will choose not to shirk if and only if $V_{E}^{N}>V_{E}^{S}$, which implies

$$
w>r V_{U}+\frac{(r+b+q) e}{q}=\widetilde{w}
$$

or alternatively:

$$
q\left(V_{E}^{S}-V_{U}\right)>e
$$

That is, unless there is a penalty associated with unemployment, everyone will shirk. Moreover, equation (6) implies that the higher the penalty (i.e. the higher $q$ or the lower the expected utility of unemployment $V_{U}$ ) the lower are the incentives for a worker to shirk. The key idea of our experimental design is, precisely, to test this result, by exogenously varying $V_{U}$ in a way that resembles the most used unemployment benefit systems worldwide.

\subsection{The Utility of an Unemployed Worker under Different Schemes}

How does $V_{U}$ differ across treatments? To answer this question, we look at the cost and benefits associated with becoming unemployed. The monetary benefits are clear. Workers assigned to Welfare or to Workfare are offered a monetary benefit $\underline{w}>0$ for being unemployed, while those assigned to Control are offered $\underline{w}=0$. Clearly, the unemployed under Welfare or Workfare are not obliged to receive the money if they wish not to. However, for simplicity, we assume that everyone entitled to an unemployment benefit claims it. In terms of costs, the three unemployment systems considered in our experiment differ only in the cost of effort $\underline{e}>0$ that the unemployed worker has to exert in order to receive the unemployment benefit $\underline{w}$ under Workfare. ${ }^{11}$ Other than this, from a purely economic perspective, the three interventions are equivalent in terms of costs.

Taking into account the economic costs and benefits, the asset equation for the expected utility of an unemployed worker under each treatment is given by:

$$
\begin{array}{cc}
\text { Workfare: } & r V_{U}=(\underline{w}-\underline{e})+a\left(V_{E}-V_{U}\right) \\
\text { Welfare: } & r V_{U}=\underline{w}+a\left(V_{E}-V_{U}\right) \\
\text { Control: } & r V_{U}=a\left(V_{E}-V_{U}\right)
\end{array}
$$

where $a$ is the job acquisition rate and $V_{E}$ is the expected utility of an employed worker, which equals $V_{E}^{N}$ in equilibrium. We can now solve (4), (7), (8) and (9) simultaneously for

\footnotetext{
${ }^{11}$ Although the unemployed could eventually shirk also while he is performing the activity required under Workfare, we assume that there is an opportunity cost of staying during the time of the activity, even doing nothing. Moreover, in our experiment, at least one experimenter was present in the room, so the unemployed could not do anything else but the activity they were assigned to.
} 


$$
\begin{aligned}
& V_{E}, V_{U}^{\text {Welfare },} V_{U}^{\text {Workfare }} \text { and } V_{U}^{\text {Control }} \\
& \qquad \begin{aligned}
& r V_{U}^{\text {Workfare }}=\frac{a(w-e)+(\underline{w}-\underline{e})(r+b)}{r+a+b} \\
& r V_{U}^{\text {Welfare }}=\frac{a(w-e)+\underline{w}(r+b)}{r+a+b} \\
& r V_{U}^{\text {Control }}=\frac{a(w-e)}{r+a+b}
\end{aligned}
\end{aligned}
$$

Substituting (10), (11) and (12) into (5) yields the Non-Shirking Condition for each treatment:

$$
\begin{array}{lc}
\text { Workfare: } & w>\Phi+\underline{w}-\underline{e}, \text { and } \\
\text { Welfare: } & w>\Phi+\underline{w} \\
\text { Control: } & w>\Phi
\end{array}
$$

where $\Phi=e+\frac{(r+a+b) e}{q}$. Note that, from a purely economic perspective, the (net) unemployment benefit under Welfare is the highest of all the unemployment systems (i.e. $\underline{w}>(\underline{w}-\underline{e})$ and $\underline{w}>0)$. Therefore, workers under Welfare should have the highest incentives to shirk. This implies the following two hypotheses:

Hypothesis 1 (Welfare vs Workfare and Control): From a purely economic perspective, the productivity of workers under Welfare should be the lowest among the three systems.

Hypothesis 2 (Workfare vs Control): From a purely economic perspective, if the productivity of workers under Workfare is higher (respectively lower or equal) than the productivity of workers under Control, it must be because the unemployment monetary benefit $\underline{w}$ is lower (respectively higher or equal) than the cost of exerting effort $\underline{e}$ in the activity under Workfare.

\section{Experimental Design}

To test these hypotheses, we developed a novel experimental design which consisted in creating employment and unemployment in the field. In this section, we briefly describe our design and we refer the reader to the Appendix, where we explain its particularities with further detail.

We employed over 300 research assistants for a one-month period in two private universities located in Bogotá, Colombia, University of Rosario (U. Rosario) and University of 
Los Andes (U. Andes). ${ }^{12}$

The job was to code news on local politicians from the online archives of the two main Colombian newspapers. We recorded daily individual productivity, measured as the number of news correctly codified.

Workers were exposed to both positive and negative employment shocks, the sequence and timing of which were unknown. Their productivity determined whether they remained employed or became unemployed in the face of negative shocks depending on their magnitude. $^{13}$

Unemployed subjects were assigned to either one of three treatments: Welfare, Workfare or Control. In the Welfare treatment, unemployed workers received one third of the daily salary in the form of an unconditional cash transfer. In the Workfare treatment, the unemployed were required to work one third of the daily shift in order to receive the benefit. ${ }^{14}$ Finally, those assigned to the Control treatment did not receive any monetary benefit.

For identification purposes we implemented the experiment in two separate stages, with the task described being the same in both. In one stage, we ran simultaneously the two identical Control treatments in each university. This constitutes the benchmark of our analysis and resembles a system in which no UBI is in place. In another stage we implemented the two UBI treatments, one in each university and with all the employees within each university receiving the same treatment. Welfare was implemented in U. Rosario and Workfare in U. Andes. To avoid spillover and contagion between subjects assigned to different treatments within the same university, we implemented the UBIs interventions (i.e. Welfare and Workfare) and the Control treatment with a one-year difference.

This design allows us to overcome several potential confounders that are intrinsic to alternative designs. For instance, a random allocation of the UBI at the individual level within universities, while probably making the subjects more comparable across treatments, would have generated spillovers and contamination inasmuch as peers or classmates from the same university are hired simultaneously to do the same job under different working conditions (Miguel and Kremer, 2004). ${ }^{15}$ By allocating subjects to treatments across uni-

\footnotetext{
${ }^{12}$ Each participant was assigned to one of eighteen groups, according to their availability of time and their university. Subjects who indicated availability in more than one slot were randomly allocated to one of these slots. Once subjects were assigned to a group, they were not allowed to change it during the entire period of the project. The distribution of groups was balanced across days, time of the day and newspaper to code. Each group would have a work shift of 1.5 hours per day, two days per week, during four weeks. See Table A.1 and appendix A.3 for a detailed description of the groups.

${ }^{13}$ Since we are interested in testing the effect of UBIs on productivity, we needed to make the probability of becoming unemployed dependent on effort. If the probability of becoming unemployed was independent on effort, there would not be a clear reason of why the UBI would affect productivity.

${ }^{14}$ The unemployment benefit was introduced in the most natural way possible. Employees were told that given their commitment to work for the whole month, the unemployed were going to be offered the possibility to receive a payment for the days they remained unemployed.

${ }^{15}$ Think of a situation in which two classmates meet and find out that they are both RAs in the same project, but one has been offered money unconditionally when unemployed while the other had to do some costly activity as a compensation for the money. Arguably, this would create an important confusion among subjects that with sufficient propagation could have jeopardized the experiment or, at least, generated all
} 
versities we may in principle lose comparability. However, as it can be seen in Table 3, the two populations are very similar in almost all the observable characteristics. More important, our design allows us to control for the remaining unobserved heterogeneity that could exist among students from the two universities. Indeed, we use a difference-in-differences specification to compare the productivity differential of the two groups based in U. Rosario (Welfare and Control) with the productivity differential of the two groups based in U. Andes (Workfare and Control). Another alternative could have been to expose the same subject to different UBIs at different moments. Although this type of design has proven to be instrumental in other labor market field experiments (e.g. Bandiera et al. 2007), we believe that in our particular setup such a design would have created a confusing and excessively artificial setting, introducing considerable noise in the data.

For the recruitment, we sent an e-mail to all social sciences students announcing the opening of temporal RA positions to work for a Research Group that we created for the purpose of the experiment. The job announcement stated that, during the one month period of duration of the project, the number of vacancies per day would vary and that their daily employment status would depend on their work performance and on the shifting labor demand. These two factors would in turn determine the final pay, and applicants were told to expect a final payment varying between US $\$ 32$ and US $\$ 90 .{ }^{16}$ The interested candidates had to fill in a pre-formatted CV online, which we used to gather socio-demographic information such us age, gender, residential address (from which we inferred the socioeconomic stratum), GPA, current job, etc.

We did not interview the candidates. The first day of sessions was exclusively an induction day, when we explained the characteristics of the job and the contractual conditions. Each working day lasted ninety minutes in total. Seventy minutes were used for coding and the rest of the time was used to save the file, send it to us by e-mail (from the work account we specially created for each of them) and filling in some questionnaires. Each session was supervised by two research assistants randomly allocated across groups. The research assistants would make sure that the session ran smoothly. They would set the computers up, record attendance, answer questions about coding, administer questionnaires, etc.

Coders' daily productivity was measured by the number of news correctly coded per day. The quality of their work was controlled by our research assistants and the workers knew this. ${ }^{17}$ After controlling for quality, the assistants would record the true productivity of

type of noise in our data.

${ }^{16}$ For a participant who would never lose his job and hence work for a maximum of 12 hours (1.5 hours per shift $\times$ two shifts per week $\times$ four weeks) the corresponding expected final payment was between 2 and 6 times the hourly minimum wage. The incentive for taking up the job was then relatively large.

${ }^{17}$ On the induction day, coders were informed that the quality of their work was going to be monitored. In principle, coders had incentives to cheat by adding fake entries into their files. To avoid this, we assigned a team of six research assistants to control the quality of the entries. Every afternoon after the working day, our assistants would randomly take at least $20 \%$ of the news coded by each coder, and control their quality following a common evaluation protocol. They would check, for example, if the entry came from real news or was invented, if the data imputed was consistent with the information in the news, etc. 
each coder and create a productivity ranking of coders per group and day. These rankings were used to determine who would become unemployed (re-employed), in case of negative (positive) shocks. Importantly, coders did not have access to these rankings until the last day of work.

\subsection{Sequence of the Experiment and Payment}

The first day was an induction day with the purpose of providing a detailed explanation of the particularities of the working scheme. During the induction, subjects received detailed instructions on how to perform the task of coding. In addition, we told them that other researchers were interested in collecting additional data, so as part of the work activities, they would be asked to answer a set of questionnaires. ${ }^{18}$ Those who accepted the terms and conditions of the job signed an informed consent and completed the first questionnaire. ${ }^{19}$

We created involuntary unemployment (shortage of vacancies) in all days except for the first and last days, when we had full employment. Unemployment increased in the second and sixth day, and decreased (i.e. vacancies were opened) during the rest of the project. Table 1 shows the unemployment rate for each working day. On the days in which there was a negative shock (i.e. an increase in the unemployment rate), the coders ranked last according to their productivity in the previous day became unemployed. In turn, in cases in which there was a positive demand shock (decrease in the unemployment rate), unemployed subjects were informed via e-mail of the number of job vacancies to be opened the next day. If they wanted to apply to fill one of such vacancies, they had to reply to that email stating so to be considered eligible. New vacancies were filled according to applicants' productivity on their last day of employment. At the beginning of every working day, two assistants would receive the subjects, check their coder's ID and inform them about their condition as employed or unemployed for that day. In order to be considered as part of the labor force, all subjects had to attend their working session on time, even those who were unemployed or had applied for a vacancy. If failed to do so (without any justified cause, such as illness), they were considered to have withdrawn from the project.

The remuneration per 90 minutes of work was the market rate for research assistants in the universities where the intervention took place. We paid subjects COP $\$ 14,250(\approx$ US\$ 8). ${ }^{20}$ This salary was over four times the minimum wage in Colombia for such working shift. In addition, there was a bonus of $\operatorname{COP} \$ 40,000(\approx$ US $\$ 22)$, for the best coder of each group, i.e. the participant who codified the largest number of correct entries in any given session. The maximum possible remuneration was US\$ 90, earned by subjects who

\footnotetext{
${ }^{18}$ Subjects were informed that their answers to these questionnaires were going to be treated anonymously and would only be used for academic purposes.

${ }^{19}$ Only one subject out of the 396 who came to the induction day, did not sign the informed consent, deciding not to take the job after the job conditions were explained.

${ }^{20}$ At the time of the experiment, the average hourly salary of a research assistant was COP $\$ 10,300(\approx$ US\$5.8).
} 
came to the induction day (US\$ 6), were employed during the eight working days (US\$ 8 $\times 8$ days $=$ US\$ 64) and won the bonus for best coder of his/her group (US\$20). The minimum possible remuneration of someone who participated in the project over the whole period was US\$ 32 if the person was assigned to a treatment with an UBI, and US\$ 14 is he/she was assigned to the Control. In order to minimize attrition, we paid the last day of the project. Additionally, subjects who withdraw from the project were entitled to request only half of the money earned by the last day they showed up to work, and this was paid too on the last day of the project.

\subsection{Interventions}

As mentioned, we implemented three different experimental interventions. The Control treatment, without any UBI, and two treatments designed to mimic the two main existing UBIs (Welfare and Workfare).

The amount of the unemployment benefit was identical in the two UBI treatments and equivalent to a third of the daily shift salary of the employed. This is of course an abstraction of the real world UBIs, in which unemployment compensations vary, even within countries, according to several characteristics of the unemployed like the spell of unemployment. While we do not think that abstracting from this variation is relevant for our experiment, we did make an effort to replicate other features of the actual implementation of UBIs. For instance, when applying for the benefit in reality, unemployed individuals have to fulfill some requirements, including signing up, filling in paperwork, and showing up regularly at some administrative office (usually to fill in additional paperwork). We had a similar procedure in our two treatments: the unemployed who wanted to receive the benefit had to show up every working day at the time and place of work. If assigned to Welfare the unemployed could leave immediately after filling in some short questionnaires, which would grant him the benefit for that day (although payable at the end of the project). ${ }^{21}$ If assigned to Workfare, the unemployed could choose whether to complete the ancillary task necessary to receive the compensation for that day or to leave, which meant turning the compensation down. ${ }^{22}$ In any case the unemployed had to show up and sign an attendance sheet. Failing to do so would be equivalent to quit the job altogether and stop being considered part of the labor force (i.e. being unable to apply for a position when new vacancies were opened).

For comparability, unemployed coders in the Control treatment were also required to show up every working day at the time and place of work if they wanted to be considered

\footnotetext{
${ }^{21}$ We used the questionnaires to measure various psychological traits that we use to test the mechanisms behind our main result.

${ }^{22}$ The task, which lasted 30 minutes, was to place letters in envelopes and paste on them randomly assigned (real) postal addresses. We manipulated the content of the letter in two sub-treatments. A Charity sub-treatment used letters that asked for donations to a social NGO. A Placebo sub-treatment used letters to publicize the business of a local private firm. While the existence of these sub-treatments within the Workfare treatment does not affect the incentives exploited for this paper, these data will be used in subsequent companion papers.
} 
part of the labor force. They were invited to leave immediately after filling some short questionnaires. This process did not entitled them any money.

\section{Sample and Data}

After releasing our call for research assistants we received 732 applicants who were available to work on the time slots we opened. We recruited 470 on a first-come first-served basis, 100 for Welfare, 200 for Workfare, and 170 for Control (of which 90 in U. Rosario and 80 in U. Andes). ${ }^{23}$

Since the experiment lasted a month, there was some attrition. Table 2 summarizes the size of the sample for the different treatments across different stages. For instance, of the 470 recruited (who were sent a confirmation email stating that their application was successful), $84 \%$ showed up on the first day, when we explained in detail the characteristics and conditions of the job. In spite of the fact that all of those who attended the induction (except for only one applicant) "accepted the job" and signed a consent form, $23 \%$ of them did not show up to the first day of work. In all, we started the project with 307 subjects.

Of the starters, about 19\% in the UBI treatments and $47 \%$ in the Control treatment dropped out between the first and the last day of activities. They did so by not showing up to the place and time of work in at least one working day, regardless of their employment status. ${ }^{24}$ However, these dropouts are not likely to significantly bias our results: On the one hand, the attrition rates reported in the last row of Table 2 are not significantly different between Welfare and Workfare, and between Control in U. Rosario and Control in U. Andes. $^{25}$ Most importantly, Panel A of Table 4 reports the average productivity on the first day of work of those who dropped out and those who remained in the project until the last day, by university and treatment. It also reports the difference in the average first day-productivity between the dropouts and the finalizers. Those who dropped out were in all cases significantly less productive than those who remained in the project. This rules out the possibility that the observed treatment differences in productivity are driven by the fact that those who dropped out in Workfare were the most productive workers and those who dropped out in Welfare were the least productive ones. Additionally, in section 5 we show that if we restrict the sample to those subjects who stay throughout the project, our results hold.

The sample composition in terms of baseline individual characteristics, psychological measures and starting productivity is reported in Table 3. The information about the indi-

\footnotetext{
${ }^{23}$ As mentioned, in Workfare we implemented two different sub-treatments that had to do with the contents of the letter to be put in envelopes. We recruited 100 subjects per sub-treatment.

${ }^{24}$ This difference is not surprising as it made little sense for the unemployed to show up to work without the incentive of receiving a monetary compensation in the Control treatment. However, for comparability we had to keep the design across treatments identical.

${ }^{25}$ The p-value of the t-test of mean differences in the attrition rate across universities is 0.38 for the UBI treatment and 0.67 for the control.
} 
vidual characteristics (Panel A) was gathered from the pre-formatted CV which applicants had to fill in online in order to apply for the job. The psychological measures (Panel B) were collected from the questionnaires that the participants filled in during different stages of the project. The initial productivity (Panel C) is that recorded on the first day of work for each individual. The students recruited in each university were quite similar in most respects. We see initial differences between the two groups only in terms of gender, and average socioeconomic status of the coders. ${ }^{26}$ The sample from U. Rosario displays a larger prevalence of female coders relative to U. Andes in both, the control stage and the UBI stage. In turn, coders from U. Andes are relatively wealthier in both stages. We control for these variables throughout our empirical analysis.

In contrast, we see no initial differences across universities in terms of age, average GPA, whether the student currently has another job, or whether the major of study is related to economics (i.e. economics, finance or business) versus other social sciences. Importantly, within universities there are no significant differences in any of the individual characteristics across stages, which provides support to our empirical strategy. In addition, as indicated by Panels $\mathrm{B}$ and $\mathrm{C}$, we do not observe differences across universities either in terms of the psychological traits that we collected at the start of the experiment, or the innate ability to perform the task (as measured by the productivity in the first day). In Panel B we focus on two psychological variables: self-esteem and job satisfaction. Self-esteem measures subjects' overall evaluation of own's worthiness or value. It was measured using a validated Spanish version of the Rosenberg's (1965) Self-Esteem Scale (RSES), one of the most widely-used self-esteem measures in social science research. ${ }^{27}$ To measure job satisfaction we used a modified version of Macdonald and MacIntyre (1997) Job Satisfaction Scale. ${ }^{28}$

The fact that the students recruited in both universities are overall very similar in terms of a large number of characteristics is not surprising since both universities are private, offer roughly the same majors within the social sciences, target students from the same backgrounds, and are among the best universities in Colombia. The fact that the average initial productivity does show significant differences within universities and across treatments is precisely one of our main findings, as will be clear in the next section.

\footnotetext{
${ }^{26}$ Neighborhoods in Bogotá have a score from 1 to 6 (called strata) which is used to price discriminate the tariff charged for public services. People who live in strata 5 and 6 (and to some extent 4) subsidize the utilities of those living in strata 1 and 2 . Real state and rent prices are positively correlated with this stratification. Therefore, the income level of a household is highly correlated to the stratum of her neighborhood of residence. Hence the use of this proxy in the absence of objective household income or consumption data. Importantly, the stratum is not self-reported. On the contrary, in the pre-formatted CV that applicants completed online, they reported their address of residence. We looked up each address on a map to determine the respective stratum.

${ }^{27}$ The RSES is a compound of ten items answered on a four-point scale ranging from strongly agree to strongly disagree. The Spanish version of the RSES scale was validated by Martin-Albo et al. (2007) and has been shown to have satisfactory levels of internal consistency and temporal stability in a population of Spanish university students. We only changed some few words so that the scale better matched Colombian use of the Spanish language.

${ }^{28}$ We shortened and adapted this scale to the specificities of the job. The resulting scale is compounded of six items, answered on a five-point scale ranging from strongly agree to strongly disagree.
} 


\section{Results}

The aim of this paper is to evaluate whether and how UBIs in general and the type of UBI in particular affect the productivity of workers. Our measure of productivity is the number of news correctly coded by each subject in each working session. Figures 1a and $1 \mathrm{~b}$ show the average daily productivity by university in the control stage and in the UBI stage respectively. In turn, Panel B of Table 4 shows the average productivity of the entire working period across stages and universities for the whole sample and for the sample that excludes the subjects who dropped out between the first and the last days of work. Note that within each university the productivity of coders is higher in the UBI stage than in the control. This suggests that having an unemployment benefit, regardless of its type, increases workers' productivity.

In addition, Figure 1a shows that in most working days of the control stage, the average productivity of the employees in U. Andes is slightly higher than in U. Rosario, Figure 1b, on the contrary, shows that in the UBI stage there is a swap in the productivity advantage and coders of U. Rosario (who worked under a Welfare scheme) are more productive than their peers at U. Andes (under Workfare) in most working days. Indeed, according to Table 4 the average productivity of the entire working period in the control stage is about 8 less news per day in U. Rosario compared to U. Andes. In contrast, the average productivity of the entire working period in the UBI stage is about 16 more news per day in U. Rosario (Welfare) compared to U. Andes (Workfare). This observation, which is robust to looking at the entire sample or at the sample net of dropouts, implies that the productivity gain obtained in the Welfare scheme is higher (24 news so) than that obtained in the the Workfare scheme, a finding that is more striking given the fact that the average productivity of the first day of work does not significantly differ across universities in neither stage (see Panel C of Table 3).

We now investigate further these two findings, namely that the presence of any UBI stimulates productivity and that this stimulus is larger in schemes with unconditional compensations. For this purpose, we estimate a difference-in-differences model that, controlling for individual characteristics, allows us to identify both the differential productivity of each UBI relative to the Control treatment, as well as the additional productivity differential that stems from being under a particular UBI relative to the oder. The later is indeed our main interest: we want to shed light on which unemployment compensation scheme (and for what reasons) is more productivity enhancing and hence has potentially larger economic benefits.

Recall, however, that our experiment follows a between-subjects design and hence each subject is either treated (by working under one of the two UBIs) or non-treated (by working under a scheme with no compensation). That is, to avoid spillovers and contagion between treated and control groups within each university, we do not have a panel of subjects some of which were first non-treated and then treated. However, recall from Table 3 that the 
samples of coders are balanced both across universities and, within them, across stages. This is so in terms of a large set of observable characteristics, including for instance initial self-esteem and initial productivity. This ensures that any result we may find with this approach is solely driven by the effect of the UBI treatments. ${ }^{29}$ Pooling the data across individuals and working dates we estimate the following regression model:

$$
y_{\text {itus }}=\alpha+\beta_{1} \text { Rosario }_{u}+\beta_{2} U B I_{s}+\beta_{3}(\text { Rosario } \times U B I)_{u s}+\delta^{\prime} X_{i t u s}+\epsilon_{i t u s}
$$

where $y_{i t u s}$ is the productivity of individual $i$ on working session $t$, in university $u$ and experimental stage $s$; Rosario $u$ is a dummy variable that takes value of 1 for subjects in $\mathrm{U}$. Rosario and zero for participants in U. Andes; $U B I_{s}$ is a dummy variable that takes value of 1 for subjects who participated in the UBI stage and zero for those in control stage; and $X_{i t u s}$ is a vector of controls that include gender, socio-economic stratum fixed effects and day fixed effects (hence the $t$ subscript). These fixed effects account, respectively, for any omitted characteristic that is common to all individuals with the same socioeconomic background and for any aggregate shocks that may affect all subjects on any working day (including potential learning over time). Finally note that the interaction between Rosario and $U B I$ picks up the subjects who were exposed to the Welfare treatment in the UBI stage.

Importantly, our design allows us to identify not only the effect on productivity of the workers who experienced unemployment (i.e. a direct effect), but also to study whether, in anticipation of the possibility of losing one's job, the presence of an UBI affects the productivity of workers who never become unemployed (i.e. an indirect effect). Thus, in addition to estimate equation (16) on the entire experimental sample, we estimate it on the subsample of returners (by looking at their productivity on the day they went back to work) and on the subsample of those who kept their job throughout the experiment (which we call "always employed").

Table 5 reports the regression results for the three samples of interest. To investigate the extent to which the individual characteristics may confound the estimates, the odd columns include no controls and the even columns include the full set of controls in $X_{\text {itus }}$. The estimated coefficients are remarkably stable when the controls are included. ${ }^{30}$ Columns 1 and 2 report the results from estimating equation (16) on the entire sample of subjects.

\footnotetext{
${ }^{29}$ In all the regressions we control for the characteristics that turned out to be significantly different across universities. In particular, we include a dummy variable that captures the gender of the coder as well as stratum fixed effects that correct for any heterogeneity across subjects that is correlated with their socioeconomic status.

${ }^{30}$ To address any potential inference problem due to serial correlation, we report henceforth results using robust standard errors, clustered at the group level. We cluster at the group level because each subject was competing with the rest of participants within his group when it came to decide who would be laid off. If subjects talked to each other after a coding session they could roughly estimate the effort-minimizing productivity level needed to keep the job.
} 
First, note that the estimated coefficient associated with the U. Rosario dummy ( $\beta_{1}$ in the equation) is not significant. This is equivalent to saying that the average productivity of coders across universities does not differ in the control stage. ${ }^{31}$ Second, the estimated coefficient associated with the $U B I$ stage dummy $\left(\beta_{2}\right)$ is positive and significant, suggesting that, within U. Andes, coders who worked in the UBI stage (i.e. under the Workfare treatment) are about 23 news more productive than their counterparts assigned to the Control treatment. Third, the increase in productivity in the UBI relative to the control stage is larger in U. Rosario. Indeed, workers under Welfare coded almost 24 news in excess of the extra news coded by workers under Workfare $\left(\beta_{3}\right)$. Note that the magnitudes and significance of these figures are robust to adding the day fixed effects and the individual controls. Recall that the latter include a gender dummy and dummies that capture the socioeconomic status of each coder.

Hypothesis 1 in Section 2 states that under a purely economic perspective, the observed productivity under the Welfare treatment should be the lowest among our experimental groups. Our results reject this hypothesis. In fact, the estimate of $\beta_{3}$ implies the opposite: the productivity of workers under Welfare is the highest. We consider this to be the main result of the paper, namely that the productivity of workers under the Welfare UBI is the highest among the three unemployment compensation systems that we examine.

Hypothesis 2 compares the effect of being assigned to the Workfare UBI vs. being in the Control treatment. According to it, if the productivity of those assigned to Workfare is higher than the one observed for the Control group, it must be that the unemployment benefit is lower than the cost of the effort required to be entitled to the benefit (i.e. $\underline{w}<\underline{e}$ ). Our estimate of $\beta_{2}$, which is positive and significantly different from zero, suggests this to be the case.

There are two possible channels through which the unemployment benefit system may affect the productivity of workers. There is on the one hand the direct effect, or the effect of being exposed to unemployment under the different schemes. On the other hand, the indirect effect is the incentive that the compensation scheme has on the workers that remain employed by making them anticipate the costs that they would face if being laid off. We explore the relative importance of these two channels in columns 3 through 6 of Table 5 .

Given the results presented in columns 1 and 2 of Table 5, if the direct effect is empirically relevant then it must the case that workers who have experienced unemployment are more productive when they return to work if they are employed under an UBI scheme (in particular under Welfare) than under a scheme with no unemployment compensation. To see this we estimate equation (16) on the subsample of subjects who were unemployed and then returned to work. To make our test more stringent, we focus on their productivity on the day of return. Column 3 provides some weak support for the existence of such di-

\footnotetext{
${ }^{31}$ The constant can be interpreted as the average news coded in U. Andes during the control stage, which in this case is equivalent to almost 42 news. $\beta_{1}$, represents the additional news coded in U. Rosario.
} 
rect effect, at least for the subjects working under Welfare: On the return day, formerly unemployed re-hired workers under Workfare are not more productive than their Control counterparts in U. Andes (the estimate of $\beta_{2}$ is not significant). However, re-hired workers under Welfare coded almost 18 news more than similar subjects in the other experimental groups (see the estimate of $\beta_{3}$ ). Column 4 confirms that this finding is robust to adding individual level controls. ${ }^{32}$

We now study the empirical relevance of the indirect effect. To that end we estimate equation (16) on a sample restricted to the subjects that did not lose the job at any stage in the experiment, and hence that we call the always employed. The results, reported in columns 5 and 6 of Table 5, are very similar to those obtained with the entire sample (columns 1 and 2), but with somewhat larger magnitudes. Thus, among the workers who remained always employed, those employed under an UBI are more productive than those that are offered no unemployment benefit (about 27 news more productive in the estimation that includes controls -column 6), and this additional productivity of the UBI workers is larger (over 30 news larger relative to Workfare) for coders working under the Welfare UBI. This result provides support for the indirect effect and suggests that workers can anticipate the disutility of being unemployed without the need to actually experience unemployment, and that the expected disutility is highest under Welfare thus making them exert higher effort when employed.

The results presented so far suggest that the effects observed for the whole sample of participants seem to be driven mainly by the behavior of the subsample of coders that remained employed during the entire experiment, and hence by the indirect effect. First, for the subsample of returners there is no evidence that workers under Workfare are more productive than workers hired with no unemployment compensation. In contrast, this is the case for the subsample of always employed. Second, while both in the subsample of returners and in the subsample of the always employed the average productivity of the coders hired under Welfare is larger than the productivity of the the coders working under the other two unemployment schemes, this edge is 80 percent higher in the subsample of the always employed relative to that of the returners, and it is statistically more significant.

\subsection{Robustness}

As discussed in section 4, due to the nature of the experiment, we experienced some attrition between the first and the last working days. Recall from Table 2 that while attrition rates do not differ statistically across universities in neither the UBI nor the control stage, they are larger for workers assigned to the Control treatment. ${ }^{33}$ Recall also that in all

\footnotetext{
${ }^{32}$ Note that the estimated coefficient of the Rosario dummy in column 3 is negative and significant, suggesting that the U. Rosario coders under Control are less productive than their U. Andes counterpart when they return to work after being laid off. This nuance however disappears when the individual controls are included (column 4).

${ }^{33}$ This is because, in order to keep the design comparable across treatments, unemployed workers in the Control treatment had to show up every working day and sign their attendance, but did not receive a
} 
experimental groups, dropouts are significantly less productive than the sample of finalizer subjects (Panel A of Table 4). ${ }^{34}$ This rises the concern that the results reported in Table 5 may be contaminated by attrition.

To rule out this possibility we replicate the analysis by considering only the subsample of subjects who did not dropout, which we call "finalizers", as they stayed until the last day of the project. The results, reported in Table 6, are remarkably similar to our benchmark results: i) Coders hired under an UBI scheme are on average more productive than coders who are offered no unemployment compensation; ii) Relative to the Control coders, the productivity gain of coders assigned to Welfare is larger than that of Workfare coders; iii) There are no differences in the productivity of Control coders in U. Rosario and U. Andes once individual controls and day fixed effects are accounted for. Again these patterns are mainly explained by the indirect effect or the expectations about the unemployment conditions of workers who do not lose their job (columns 5 and 6 ). Indeed, the only substantive difference with Table 5 is that on the day they returned to work, formerly unemployed under Welfare are not significantly more productive than workers of other unemployment schemes (columns 3 and 4$).{ }^{35}$

\section{Potential Mechanisms}

\subsection{The Psychological Costs of Unemployment}

As shown above, our main findings contradict the standard economic predictions, as summarized by Hypothesis 1. In this section we discuss a potential explanation that can account for this contradiction. We do so by introducing psychological features to the standard economic model presented in section 2 .

While the standard economic model abstracts from the psychological costs of unemployment, there is extensive evidence on the negative effect that unemployment has on the psychological well-being of the unemployed (see Darity and Goldsmith, 1996 for a review). If the psychological costs involved in each experimental intervention differ from each other, this could potentially explain the sharp productivity differences observed in the data.

What are the psychological costs of unemployment and how are these costs likely to vary across each intervention? The literature of psychology and behavioral economics identifies three major sources of psychological costs of unemployment: idleness, shame and social stigma. As Jahoda $(1981,1988)$ points out, being idle while unemployed is psychologically destructive because the individual is deprived of the "byproducts of the work environment". Employment implies regularly shared experiences and contact with people outside the core family; links individuals to goals and purposes that transcend their own; defines aspects

\footnotetext{
compensation in exchange.

${ }^{34}$ This is because low productivity implies a higher probability of being laid off after negative demand shocks and a lower probability of being hired back after positive shocks.

${ }^{35}$ The p-value of the estimated $\beta_{3}$ in the model that includes controls (column 4 ) is 0.106 .
} 
of personal status and identity; and finally, employment enforces activity. In words of Jahoda (1982), "even unsatisfactory employment is preferable to the absence of work" (Cited in Darity and Goldmisdt, 1996, p. 124). Since this cost is associated with pure idleness, there are only two interventions in which it may in principle exist: Welfare and Control. The monetary compensation offered in Welfare should somehow compensate for this cost, so if this psychological cost was the only one present in our experiment, we should have observed productivity under Control being higher than productivity under Welfare. However, productivity under Welfare more than doubles productivity under Control in our experiment, which suggest that the cost of idleness pointed out by Jahoda is not the key factor (or at least not the sole factor) driving our results.

The second source of psychological cost comes from the shame associated with unemployment. Shame is an overwhelming and unpleasant emotion associated with feelings of worthlessness, inferiority, and a damaged self-image (Ausubel, 1955). The occurrence of shame amongst unemployed people was described by numerous scholars, especially for the case of white collar workers (see for example Fineman, 1983). This is particularly relevant for the population in our experiment, that consists of well-educated subjects who become unemployed because of their low productivity compared to their peers.

The third possible source of psychological cost is the social stigma of being unemployed (Walsgrove, 1987). Social stigma can be defined as a disapproval of personal characteristics or beliefs that are against cultural norms. Jobless people usually feel at fault, and are often stigmatized as being lazy or useless (Letkemann, 2002), all factors that are known to affect self-worth.

It is plausible that the unemployed in our project may have experienced some degree of shame or stigma. But to what extend could these psychological effects have differed across treatments? If the psychological costs caused by shame or stigma were higher under Welfare than under either Workfare or no UBI, and high enough to outweigh the monetary benefits of Welfare, then they could provide a plausible explanation of the productivity differences we observe across treatments. We illustrate this by revisiting the simple economic model of section 2 and examine to what extent Hypotheses 1 and 2 change when the aforementioned psychological costs are incorporated in the model.

First, we incorporate a psychological cost of being idle, $\gamma>0$, to the costs of being unemployed under Welfare (see section 2, equation 14) and under Control (equation 15), since in both these systems the unemployed is idle. ${ }^{36}$

Second, above and beyond the cost of being idle, recent literature of behavioral economics reports evidence that people feel more comfortable when they pay a price for their mistakes or misbehavior than when they do not. For example, Gneezy and Rustichini (2000) show that introducing a monetary fine for late-coming parents in day-care centers increased

\footnotetext{
${ }^{36}$ Note that there are no reasons to believe that the unemployed assigned to Workfare suffer from the psychological cost of being idle, because they can pursue an activity).
} 
the number of late-coming parents significantly. It is as if the fine washes out the shame or guilt parents may feel when they misbehave. In our setting, the costly activity required in Workfare can be understood as a fine the unemployed are willing to pay to wash out their guilt or shame of being of low relative productivity. This possibility is clearly not present under the Welfare intervention, where the unemployed not only is prevented from the possibility to pay a fine to wash out any negative feelings associated with their low productivity, but on top of that, he receives money unconditionally. Based on this literature, we introduce an additional psychological cost $\lambda>0$ to being unemployed under Welfare. ${ }^{37}$ Thus, taking into account these psychological costs referred to in the literature, we revisit the non-shirking conditions specified in equations (13), (14) and (15) as follows:

$$
\begin{array}{rc}
\text { Welfare: } & w>\Phi+\underline{w}-\lambda-\gamma, \\
\text { Workfare: } & w>\Phi+\underline{w}-\underline{e}, \text { and } \\
\text { Control: } & w>\Phi-\gamma,
\end{array}
$$

Our main empirical finding is that workers under Welfare are more productive than under Workfare, who in turn are more productive than workers assigned to Control. This implies that, ceteris paribus, the cost of being unemployed under Welfare is higher than the cost of being unemployed under Workfare (i.e. $-\underline{w}+\gamma+\lambda>\underline{e}-\underline{w}$, or $\gamma+\lambda>\underline{e}$ ), and that the cost of being unemployed under Workfare is higher than the cost of being unemployed under Control (i.e. $\underline{e}-\underline{w}>\gamma$, or $\underline{e}>\gamma+\underline{w}$ ). These two conditions together imply that $\gamma+\lambda>\gamma+\underline{w}$, or $\lambda>\underline{w}$. Hence, our results imply that the additional psychological cost of being unemployed under Welfare (i.e. $\lambda>0$ ) must not only exist, but it must be substantially high as to outweigh the monetary benefit $\underline{w}$ offered in the two UBIs.

Importantly, the proposed psychological mechanism is supported by the data. Using the standardized psychological questionnaire applied to the subjects at different moments of the experiment, we look at how the initial "self-esteem", which according to Table 3 is balanced across treatments, is affected by the different compensation schemes. Specifically, in Table 7 we compare the change in self-esteem between the first day of work until day 6 (when the last unemployment shock took place) of the coders who remained unemployed through days 2 to 6 , to that of the coders who have not lost their job within that period. Again, for robustness we do so for both, the entire sample of workers (Panel A) and for the subsample of finalizers (Panel B). ${ }^{38}$ We find that, while the change in self-esteem is not

\footnotetext{
${ }^{37}$ Note that the there are no reasons to believe that the unemployed assigned to Workfare suffer from shame/guilt of being paid for doing nothing (because, indeed, they are paid only if they do something).

${ }^{38}$ Because comparisons are made within universities and treatments, and for subsamples of employed and unemployed, we are left with relatively few observations within each bean. Thus, in Table 7 we report the results of the Mann-Withney test. However, all these results are however robust to using the standard T-test
} 
significantly different across universities and treatments for neither the unemployed or the employed, experiencing unemployment does imply a drop in self-esteem, albeit only under Welfare. This drop in self-esteem could in principle be associated to shame or stigma. While distinguishing between these two effects is out of the scope of this paper, we conjecture that what we observe is more likely to correspond to shame than to stigma. Indeed, even when some degree of stigma presumably exists in both UBIs, the feeling of shame is more likely to be present under Welfare, where the unemployed were offered an unconditional monetary benefit for being the lowest productive coders. Moreover, it has been shown how welfare stigma can lead to the perpetuation of welfare use (Page, 1984), due to its effect on selfesteem. ${ }^{39}$ In principle, a Workfare UBI can mitigate such effect by offering the unemployed the chance to contribute with their effort and time to an activity with a clear purpose.

Hence, the fact that we observe an actual drop in self-esteem only when the unemployed is assigned to Welfare, not only provides evidence on the existence of $\lambda>0$, but it also suggests that this extra psychological cost comes from the experience of shame.

Arguably, in our experiment the unemployed had the chance to avoid these psychological costs by choosing not to receive the benefit. In principle, the unemployed were free to do so, although nobody in our experiment actually chose that option. This suggests that the sole fact of being part of the Welfare system was enough to affect their self-esteem, and coders did not do anything to avoid it but to work hard when they were employed. Declining to receive the benefits at the end of the project seemed not to be a device used to protect self-esteem. One possible explanation for this behavior could be that once the self-esteem was damaged, rejecting or accepting the benefit would not restore it. ${ }^{40}$

\subsection{Alternative mechanisms}

We have shown that the presence of psychological costs can explain the observed differences in productivity across experimental groups. Nevertheless, there may be alternative explanations also consistent with our findings. In this subsection we explore these.

The first potential alternative mechanism is reciprocity, in the form of gift exchange. It could be that the unemployed in Welfare felt treated nicely because they were offered money for doing nothing and they reciprocated with high effort when they were employed.

Our data do not seem to support this mechanism. One would expect that coders who experienced unemployment are those more willing to reciprocate, because are they have experienced the special treatment. However, as we have already shown, most of the difference in productivity between treatments comes from the coders who remained employed

of differences in means.

${ }^{39}$ Social psychologist make an important characterization of shame that distinguish it from guilt, regret and embarrassment: shame is the only negative emotion that involves a drop in self-esteem (see Welten, Breugelmans and Zeelenberg, 2013). So the drop of self-esteem we observe is a necessary, though perhaps not sufficient, condition for the existence of shame.

${ }^{40}$ We acknowledge that in real life scenarios, however, some people would never claim an unemployment benefit, precisely to avoid the psychological costs we just showed existed in our experimental setting. 
throughout the duration of the project (i.e. the indirect effect), and who in principle have less reasons to reciprocate. If anything, they could only reciprocate good intentions. Figure 2 shows the daily average productivity for the employees who remained always employed in the Welfare treatment in U. Rosario and in the Workfare treatment in U. Andes. While there are no differences in the performance at the beginning of the project, after the first day of work subjects in Welfare perform better than those in Workfare. Moreover, the fact that the productivity wedge disappears on the last day of activities (mainly through a large drop in the productivity of the Welfare subjects) is not consistent with the reciprocity story. Indeed, recall that in the last day of the project there were vacancies available for everyone, so everyone who was unemployed and applied came back to work. If it was true that the motivation to reciprocate was higher under Welfare than under Workfare, we would expect productivity under Welfare to increase even further in the last day. We observe the opposite.

Importantly, the closure of the productivity gap in the last working day, via a drop in the productivity of the Welfare coders, confirms that the effect in productivity during the project can be attributed entirely to the treatments. Indeed, in the last day the incentives were exactly the same in the two treatments because there was no possibility of becoming unemployed.

The second mechanism we consider has to do with job satisfaction. From a purely economic perspective (i.e. without taking into account the psychological costs), the cost of unemployment under Workfare is higher than under Welfare because it requires some positive effort in exchange of the same compensation. Thus, coders under Workfare could have experienced higher pressure to perform well than those under Welfare, which in turn could have translated into a worse performance. ${ }^{41}$ If this was true, then job satisfaction would be lower for workers under Workfare.

Using a measure of job satisfaction, collected in various moments of the intervention with standardized questionnaires, we test the validity of this mechanism. The results are reported in Table 8. We find that workers are equally satisfied across treatments and that this is so both, at the beginning and at the end of the experiment (day 1 and day 8). Moreover, this is true independent of whether we look at all the workers employed on the days we measured job satisfaction (Panel A), or at the sample of workers who never experienced unemployment (Panel B). Hence, we rule out differential psychological stress as a possible explanation of our results.

A third alternative explanation concerns treatment differences in group collusion. Bandiera et al. (2005) show that workers may tacitly collude as a group and reduce their individual productivity, as they internalize the externality of their performance on their colleagues. If the social preferences/ties in the Workfare group were stronger than in the Welfare one, this could be the reason for the observed productivity differences. However, note that in our

\footnotetext{
${ }^{41}$ See Oswald et al (2011) for evidence on how happiness affects productivity.
} 
setting, an altruistic worker who wants to increase the expected income of their colleagues will choose to exert zero effort and when unemployed, he will choose not to apply to fill in the new vacancies. Therefore, social ties could only be a reason for dropping out (or stay in unemployment throughout the project), but does not explain differences in productivity. Recall from Table 2, that we do not observe differences in the dropout rate across universities. So, we rule out this alternative explanation.

Finally, we explore whether the behavior of the unemployed when it comes to apply for new vacancies is consistent with our results on productivity and with the psychological mechanism that, we argue, explains them. We thus look at the application rates across treatments. Focusing on Panel A of Table 9, which looks at the application rate in working day 7 within the two UBI treatments, we find that subjects under Welfare apply on average less than under Workfare. ${ }^{42}$ This is robust to including the usual individual controls (column 2). At first, this may seem at odds with the mechanism proposed: If the cost of being unemployed under Welfare is indeed so high, coders would not only try to avoid it working hard (our main finding), but they would also apply more aggressively when new vacancies are opened. However, the results of Table 9 are perfectly consistent with the main mechanism put forward, namely that an unconditional monetary benefit increases productivity through its negative effect on self-esteem. It is precisely this negative effect on self-esteem what may discourage people to apply for new positions. ${ }^{43}$ We test this conjecture by looking at the effect on the probability of applying to new vacancies on day 7 on the interaction between Welfare and the change in self-esteem. As shown in columns 3 and 4 (without and with controls, respectively) of Panel A, the interaction term is positive and significant. This means that the unemployed under Welfare has a lower probability of applying to a new vacancy if his self-esteem drops. Hence, Welfare acts as a self-esteem underminer. Conversely, Workfare may be understood as a self-esteem buffer.

Interestingly, when we estimate the same regression for the application rate for the vacancies opened for day 8 (the last day of work, when there is full employment), we observe that neither the Welfare treatment nor its interaction with the change in selfesteem matters anymore (see Panel B of Table 9). This result is consistent with the theory of Köszegi (2006): the only way in which self-esteem can be damaged further is when the unemployed apply for a job unsuccessfully. ${ }^{44}$ This certainly is a possibility in day 7 , but it is not in day 8 , when the unemployed do not compete for jobs anymore since there is full-employment. For this reason, self-esteem will not be harmed anymore, and hence the

\footnotetext{
${ }^{42}$ As will become clear, we focus on day 7 applications because we want to examine how applications interact with the change is self-esteem, which is measured on the first and the sixth day of work.

${ }^{43}$ The emotional distress of joblessness may create a "discouragement" effect is consistent with Seligman's (1975) idea of learn helplessness.

${ }^{44}$ This is what psychologist call situation avoidance: 'action (or inaction) that purposely avoids the acquisition of economically valuable information relating to one's personal characteristics - even when the cost of acquiring such information appears to be zero" (see Andolfatto, Mongrain, Myers, 2009). If the individual cares about how he views himself, and acquisition of information affects this view, then he will try to protect his self-esteem by avoiding the situation.
} 
unemployment institution does not affect the application rate.

\section{Conclusion}

This paper uses a field experiment to study, for the first time, the effect of unemployment benefits institutions on individual productivity. Our experimental design allows us to mea-

sure workers' productivity under the two most widely used unemployment benefit schemes (workfare and welfare) and under a situation without unemployment benefit.

Contrary to the conventional economics perspective, we observe that an unconditional unemployment benefit makes workers more productive than a conditional compensation scheme, and that both schemes make workers more productive than having no unemployment benefit. We provide evidence consistent with the hypothesis that the difference in productivity comes from the fact that workers dislike being paid while idle when they are unemployed. This situation affects their self-esteem, presumably due to the shame or the stigma associated with an unconditional monetary benefit. These psychological costs act as a powerful non-monetary incentive which induces workers to work harder to avoid unemployment.

Although self-esteem is conceived to be a stable and enduring personality treat of the individual, it may be altered by major life changes or traumatic events (Gergen, 1978; Akerlof and Yelen, 1985). Our findings provide clear cut evidence that unemployment can affect self-esteem in a considerable way, even in a short-period of time, and in a situation in which working is not the main activity of the person. Hence, our results can be understood as a lower bound of the potential effects of real life unemployment institutions on the psychology of the unemployed, and on productivity.

Also importantly, our findings imply that an institution such as Workfare can act as self-esteem protector by keeping the unemployed actively working for a purpose. However, this comes at the cost of a lower productivity.

Care should be taken in generalizing the results of this experiment to other situations and people. Although using a real job in a natural environment gives higher external validity than an artificial task in a lab setting, we still acknowledge that our population is far from being representative of all the labor force. However, our sample is arguably representative of an important segment of the world population who currently suffers from unemployment, namely well-educated youth. According to the European Commission (2013), youth unemployment rate in Europe is more than twice as high as the adult one. The chances for a young unemployed person of finding a job are low and when young people do work, their jobs tend to be less stable. Moreover, the unemployment among youth with academic degrees is an increasing problem both in developed and the developing countries. In Africa, for example, young people with a university education have the highest unemployment rates (African Economic Outlook, 2013). 
All in all, we believe that our analysis highlights important aspects that should not be disregarded in the public policy discussion on social protection institutions. For instance, welfare programs have been criticized for creating dependence and discouraging search for new employment. Our findings suggest that such creation of dependence may be originated and perpetuated due to a drop on self-esteem. Moreover, this psychological effect may serve as a screening device, keeping low productivity workers out of the activity where they are relatively less productive. On the other hand, our analysis suggests that if policy makers care only about productivity, then a welfare-type UBI may be the way to go, as long as the effect on self-esteem does not affect the supply of labor in other activities.

\section{References}

[1] Abbring, Jaap H., Gerard J. van den Berg. and Jan C. van Ours. 2005. "The effect of Unemployment Insurance Sanctions on the Transition Rate from Unemployment to Employment." Economic Journal, 115 (505): 602-630.

[2] Acemoglu, Daron and Robert Shimer. 2000. "Productivity Gains from Unemployment Insurance." European Economic Review, 44 (7): 1195-1224.

[3] African Economic Outlook. 2013. Who are the Unemployed, Discouraged and Inactive Youth in Africa?

[4] Akerlof George A. and Janet L. Yellen. 1985. "Unemployment through the Filter of Memory." The Quarterly Journal of Economics. 100 (3): 747-773.

[5] Andolfatto, D., S. Mongrain and G. Myers 2009. "Rational truth-avoidance and self-esteem." Canadian Journal of Economics, 42 (1): 141-154.

[6] Ausubel, David P. 1955. "Relationships between shame and guilt in the socializing process. " Psychological Review 62 (5): 378.

[7] Bandiera, Oriana, Iwan Barankay, and Imran Rasul. 2005. "Social preferences and the response to incentives: Evidence from personnel data." The Quarterly Journal of Economics. 120(3), 917-962.

[8] Bandiera, Oriana, Iwan Barankay, and Imran Rasul. 2007. "Incentives for managers and inequality among workers: evidence from a firm-level experiment." The Quarterly Journal of Economics. 122(2), 729-773.

[9] Besley, Timothy, and Stephen Coate. 1982. "Workfare versus Welfare: Incentive Arguments for Work Requirements in Poverty-Alleviation Programs." American Economic Review, 82 (1): 249-261.

[10] Black, Dan A., Jeffrey A. Smith, Mark C. Berger, and Brett J. Noel. 2003 "Is the threat of reemployment services more effective than the services themselves? Evidence from random assignment in the UI system." American Economic Review : 1313-1327. 
[11] Boone, Jaan, Peter Fredriksson, Bertil Holmlund and Jan C. van Ours. 2007. "Optimal Unemployment Insurance with Monitoring and Sanctions." Economic Journal, 117 (518): 399-421.

[12] Darity W. Jr, and A. H. Goldsmith. 1996. "Social Psychology, Unemployment and Macroeconomics." The Journal of Economics Perspectives, 10 (1): 121-140.

[13] De Hooge, Ilona E., Seger M. Breugelmans, and Marcel Zeelenberg. 2008. "Not so ugly after all: when shame acts as a commitment device. " Journal of Personality and Social Psychology 95(4): 933.

[14] European Commission (2013). Employment, Social Affairs and Inclusion EU Measures to Tackle Youth Unemployment. June, 2013.

[15] Falk, Armin, David Huffman and Konrad Mierendorff. 2006. "Incentive Properties and Political Acceptability of Workfare: Evidence from Real Effort Experiments." mimeo.

[16] Fineman S. 1983. White Collar Unemployment: Impact and stress. Wiley, London.

[17] Fredriksson Peter and Bertil Holmlund. 2006. "Improving Incentives in Unemployment Insurance: a Review of Recent Research." Journal of Economic Surveys. 20 (3): $357-386$.

[18] Gergen, Kenneth. 1978. "The Social Construction of Self Knowledge." In Mishell, Judith, ed., The Self Totowa: Rowman and Littlefield.: 139-63.

[19] Gneezy, U., and Rustichini, A. 2000. "Fine Is a Price." J. Legal Stud., 29, 1.

[20] Gueron Judith. 1990. "Work and Welfare: Lessons on Employment Programs." Journal of Economic Perspectives, 4 (1): 79-98.

[21] International Labour Office. 2010. World Social Security Report 2010: Providing Coverage in Times of Crisis and Beyond. International Labour Office.

[22] Jahoda, Marie. 1981. "Work, Employment and Unemployment: Values, Theories, and Approaches in Social Research." American Psychologist, 36 (2): 184-91.

[23] Jahoda, Marie. 1982. Employment and Unemployment: A social-psychological analysis. Vol. 1. Cambridge University Press.

[24] Jahoda, Marie. 1988. "Economic Recession and Mental Health: Some Conceptual Issues." Journal of Social Issues, 44 (4): 13-23.

[25] Köszegi, Botond. 2006 "Ego utility, overconfidence, and task choice." Journal of the European Economic Association 4 (4): 673-707.

[26] Letkemann, Paul. 2002. "Unemployed professionals, stigma management and derivative stigmata." Work, Employment and Society. 16:511.

[27] Martin-Albo Jose, Juan L. Nuniez, Jose G. Navarro, and Fernando Grijalvo. 2007. "The Rosenberg Self-Esteem Scale: Translation and Validation in University Students." The Spanish Journal of Psychology, 10 (2): 458-467. 
[28] Macdonald Scott and Peter Maclntyre. 1997. "The Generic Job Satisfaction Scale: Scale Development and Its Correlates." Employee Assistance Quarterly, 13 (2): 1-16.

[29] Miguel, Edward, and Michael Kremer. 2004. "Worms: identifying impacts on education and health in the presence of treatment externalities." Econometrica 72(1): $159-217$.

[30] Page, Robert M. 1984. Stigma. London: Routledge and Keegan Paul.

[31] Rigotti T., B. Schyns and G. Mohr. 2008. "A Short Version of the Occupational Self-Efficacy Scale: Structural and Construct Validity Across Five Countries." Journal of Career Assessment, 16 (2): 238-255.

[32] Rosenberg, Morris. 1965. Society and the adolescent self-image. Princeton, NJ: Princeton University Press.

[33] Ochel, Wolfgang. 2005. "Welfare-to-Work Experiences with Specific Work-First Programmes in Selected Countries." International Social Security Review, 58 (4): 67-93.

[34] Oswald, Andrew, Eugenio Proto and Daniel Sgroi. 2011. "Happiness and Productivity." mimeo, University of Warwick.

[35] Prendergast Canice, 1999. "The Provision of Incentives in Firms." Journal of Economic Literature, 37 (1) 7-63.

[36] Seligman, Martin EP. 1975. "Helplessness: On depression, development, and death." WH Freeman/Times Books/Henry Holt \& Co.

[37] Shapiro, Carl and Joseph Stiglitz. 1984. "Equilibrium Unemployment as a Worker Discipline Device," American Economic Review, 74 (3): 433-444.

[38] Walsgrove D. 1987. "Policing yourself: social closure and the internalization of stigma." In The Manufacture of Disadvantage, ed. G Lee, R Loveridge. Philadelphia: Open Univ. Press

[39] Welten, Stephanie C. M., Seger M. Breugelmans and Marcel Zeelenberg. 2013. "The Self in Shame." mimeo. 


\section{Tables}

Table 1: Sequence of unemployment shocks

\begin{tabular}{lcccccccc}
\hline \hline Day & 1 & 2 & 3 & 4 & 5 & 6 & 7 & 8 \\
Shock & & - & + & + & + & - & + & + \\
\% Unemployment Rate & 0 & $\mathbf{6 0}$ & 55 & 45 & 35 & $\mathbf{6 0}$ & 50 & 0 \\
\hline \hline
\end{tabular}

Table 2: Recruitment and attrition

\begin{tabular}{lcccccc}
\hline \hline & \multicolumn{2}{c}{ UBIs } & & \multicolumn{2}{c}{ Control } & \multirow{2}{*}{ Total } \\
\cline { 2 - 3 } \cline { 5 - 6 } & U. Andes & U. Rosario & & U. Andes & U. Rosario & \\
\hline Applicants & 275 & 131 & & 80 & 246 & 732 \\
Recruited & 200 & 100 & & 80 & 90 & 470 \\
Induction & 163 & 65 & & 79 & 89 & 396 \\
Day 1 & 143 & 60 & & 48 & 56 & 307 \\
Day 8 & 114 & 51 & & 24 & 31 & 220 \\
Attrition Rate & $20 \%$ & & & & \\
\hline \hline
\end{tabular}


Table 3: Baseline sample differences across universities and treatments

\begin{tabular}{|c|c|c|c|c|c|c|c|c|}
\hline & \multicolumn{3}{|c|}{ "Within U. Rosario } & \multicolumn{3}{|c|}{ Within U. Andes } & \multicolumn{2}{|c|}{ Across universities } \\
\hline & $\begin{array}{l}\text { Welfare } \\
\text { (1) }\end{array}$ & $\begin{array}{l}\text { Control } \\
(2)\end{array}$ & $\begin{array}{l}\text { Difference } \\
(1)-(2)\end{array}$ & $\begin{array}{c}\text { Workfare } \\
(3)\end{array}$ & $\begin{array}{c}\text { Control } \\
(4)\end{array}$ & $\begin{array}{l}\text { Difference } \\
(3)-(4)\end{array}$ & $\begin{array}{c}\text { UBI } \\
(1)-(3)\end{array}$ & $\begin{array}{l}\text { Control } \\
(2)-(4)\end{array}$ \\
\hline \multicolumn{9}{|c|}{ Panel A: Individual characteristics } \\
\hline Gender $(1=\text { female })^{b}$ & $\begin{array}{c}0.63 \\
(0.06)\end{array}$ & $\begin{array}{c}0.57 \\
(0.07)\end{array}$ & $\begin{array}{c}0.06 \\
(0.09)\end{array}$ & $\begin{array}{c}0.45 \\
(0.04)\end{array}$ & $\begin{array}{c}0.40 \\
(0.07)\end{array}$ & $\begin{array}{c}0.05 \\
(0.08)\end{array}$ & $\begin{array}{c}0.18^{* *} \\
(0.08)\end{array}$ & $\begin{array}{l}0.17^{*} \\
(0.10)\end{array}$ \\
\hline Age & $\begin{array}{l}21.30 \\
(0.25)\end{array}$ & $\begin{array}{l}21.07 \\
(0.23)\end{array}$ & $\begin{array}{c}0.23 \\
(0.34)\end{array}$ & $\begin{array}{l}20.94 \\
(0.15)\end{array}$ & $\begin{array}{l}20.56 \\
(0.23)\end{array}$ & $\begin{array}{c}0.38 \\
(0.29)\end{array}$ & $\begin{array}{c}0.36 \\
(0.28)\end{array}$ & $\begin{array}{c}0.51 \\
(0.33)\end{array}$ \\
\hline Socioeconomic status ${ }^{a}$ & $\begin{array}{c}3.63 \\
(0.12)\end{array}$ & $\begin{array}{c}3.77 \\
(0.12)\end{array}$ & $\begin{array}{l}-0.13 \\
(0.17)\end{array}$ & $\begin{array}{c}4.50 \\
(0.09)\end{array}$ & $\begin{array}{c}4.34 \\
(0.16)\end{array}$ & $\begin{array}{c}0.16 \\
(0.18)\end{array}$ & $\begin{array}{c}-0.86^{* * *} \\
(0.16)\end{array}$ & $\begin{array}{c}-0.57^{* *} \\
(0.19)\end{array}$ \\
\hline GPA (1 to 5 scale) & $\begin{array}{c}3.95 \\
(0.07)\end{array}$ & $\begin{array}{c}3.94 \\
(0.04)\end{array}$ & $\begin{array}{c}0.01 \\
(0.09)\end{array}$ & $\begin{array}{c}3.98 \\
(0.03)\end{array}$ & $\begin{array}{c}3.91 \\
(0.04)\end{array}$ & $\begin{array}{c}0.07 \\
(0.06)\end{array}$ & $\begin{array}{l}-0.03 \\
(0.07)\end{array}$ & $\begin{array}{c}0.03 \\
(0.06)\end{array}$ \\
\hline Currently working $(1=\text { yes })^{b}$ & $\begin{array}{c}0.08 \\
(0.04)\end{array}$ & $\begin{array}{c}0.05 \\
(0.03)\end{array}$ & $\begin{array}{c}0.03 \\
(0.05)\end{array}$ & $\begin{array}{c}0.09 \\
(0.02)\end{array}$ & $\begin{array}{c}0.17 \\
(0.05)\end{array}$ & $\begin{array}{l}-0.08 \\
(0.05)\end{array}$ & $\begin{array}{l}-0.01 \\
(0.04)\end{array}$ & $\begin{array}{l}-0.12^{*} \\
(0.06)\end{array}$ \\
\hline Major $(=1 \text { econ. related })^{b}$ & $\begin{array}{c}0.68 \\
(0.06)\end{array}$ & $\begin{array}{c}0.55 \\
(0.07)\end{array}$ & $\begin{array}{c}0.13 \\
(0.09)\end{array}$ & $\begin{array}{c}0.69 \\
(0.04)\end{array}$ & $\begin{array}{c}0.56 \\
(0.07)\end{array}$ & $\begin{array}{c}0.13 \\
(0.08)\end{array}$ & $\begin{array}{l}-0.01 \\
(0.07)\end{array}$ & $\begin{array}{c}0.01 \\
(0.10)\end{array}$ \\
\hline \multicolumn{9}{|c|}{ Panel B: Baseline psychological characteristics } \\
\hline Self-esteem (day 0) & $\begin{array}{l}35.79 \\
(0.42)\end{array}$ & $\begin{array}{l}34.65 \\
(0.53)\end{array}$ & $\begin{array}{l}1.14^{*} \\
(0.67)\end{array}$ & $\begin{array}{l}35.81 \\
(0.27)\end{array}$ & $\begin{array}{l}35.65 \\
(0.45)\end{array}$ & $\begin{array}{c}0.16 \\
(0.54)\end{array}$ & $\begin{array}{l}-0.02 \\
(0.50)\end{array}$ & $\begin{array}{l}-1.00 \\
(0.71)\end{array}$ \\
\hline Job satisfaction (day 1 ) & $\begin{array}{l}24.19 \\
(0.46)\end{array}$ & $\begin{array}{l}24.20 \\
(0.63)\end{array}$ & $\begin{array}{l}-0.01 \\
(0.77)\end{array}$ & $\begin{array}{l}23.85 \\
(0.33)\end{array}$ & $\begin{array}{l}24.13 \\
(0.51)\end{array}$ & $\begin{array}{l}-0.28 \\
(0.65)\end{array}$ & $\begin{array}{c}0.34 \\
(0.59)\end{array}$ & $\begin{array}{c}0.07 \\
(0.82)\end{array}$ \\
\hline \multicolumn{9}{|c|}{ Panel C: Initial productivity (day 1) } \\
\hline All sample (mean) & $\begin{array}{l}29.92 \\
(2.28)\end{array}$ & $\begin{array}{l}18.13 \\
(1.44)\end{array}$ & $\begin{array}{c}11.79^{* * *} \\
(2.74)\end{array}$ & $\begin{array}{c}28.8 \\
(1.36)\end{array}$ & $\begin{array}{l}18.29 \\
(1.98)\end{array}$ & $\begin{array}{c}10.51^{* * *} \\
(2.61)\end{array}$ & $\begin{array}{c}1.11 \\
(2.57)\end{array}$ & $\begin{array}{l}-0.16 \\
(2.41)\end{array}$ \\
\hline All sample (std. dev. $)^{c}$ & 17.50 & 10.70 & $W_{0}=16.83^{* * *}$ & 16.24 & 13.75 & $W_{0}=2.00$ & $W_{0}=1.78$ & $W_{0}=1.57$ \\
\hline
\end{tabular}


Table 4: Productivity differences across universities and treatments

\begin{tabular}{|c|c|c|c|c|c|c|c|c|}
\hline & \multicolumn{3}{|c|}{ Within U. Rosario } & \multicolumn{3}{|c|}{ Within U. Andes } & \multicolumn{2}{|c|}{ Across universities } \\
\hline & $\begin{array}{c}\text { Welfare } \\
(1)\end{array}$ & $\begin{array}{c}\text { Control } \\
(2) \\
\end{array}$ & $\begin{array}{c}\text { Difference } \\
(1)-(2) \\
\end{array}$ & $\begin{array}{c}\text { Workfare } \\
(3)\end{array}$ & $\begin{array}{c}\text { Control } \\
(4)\end{array}$ & $\begin{array}{c}\text { Difference } \\
(3)-(4)\end{array}$ & $\begin{array}{c}\text { UBI } \\
(1)-(3)\end{array}$ & $\begin{array}{l}\text { Control } \\
(2)-(4)\end{array}$ \\
\hline \multicolumn{9}{|l|}{ Panel A: Day one } \\
\hline Dropouts & $\begin{array}{l}17.22 \\
(3.80)\end{array}$ & $\begin{array}{l}12.12 \\
(1.27)\end{array}$ & $\begin{array}{l}5.10 \\
(3.07)\end{array}$ & $\begin{array}{l}22.96 \\
(1.81)\end{array}$ & $\begin{array}{l}14.50 \\
(3.16)\end{array}$ & $\begin{array}{l}8.46^{* *} \\
(3.49)\end{array}$ & $\begin{array}{l}-2.38 \\
(3.35)\end{array}$ & $\begin{array}{l}-5.74 \\
(3.87)\end{array}$ \\
\hline Finalizers & $\begin{array}{c}32.2 \\
(2.48)\end{array}$ & $\begin{array}{l}23.13 \\
(2.02)\end{array}$ & $\begin{array}{c}9.07^{* *} \\
(3.56)\end{array}$ & $\begin{array}{l}30.30 \\
(1.62)\end{array}$ & $\begin{array}{l}22.08 \\
(2.21)\end{array}$ & $\begin{array}{c}8.22 * * \\
(3.67)\end{array}$ & $\begin{array}{c}1.9 \\
(2.94)\end{array}$ & $\begin{array}{c}1.05 \\
(3.00)\end{array}$ \\
\hline Dropouts-finalizers & $\begin{array}{c}-14.98^{* *} \\
(6.08)\end{array}$ & $\begin{array}{c}-11.01^{* * *} \\
(2.50)\end{array}$ & $\begin{array}{l}-3.96 \\
(6.18)\end{array}$ & $\begin{array}{c}-7.34^{* *} \\
(3.34)\end{array}$ & $\begin{array}{l}-7.58^{*} \\
(3.85)\end{array}$ & $\begin{array}{c}0.24 \\
(5.48)\end{array}$ & $\begin{array}{c}7.63 \\
(6.79)\end{array}$ & $\begin{array}{c}3.43 \\
(4.49)\end{array}$ \\
\hline
\end{tabular}

Panel B: Average across days

\begin{tabular}{lcccccccc} 
All sample & 80.82 & 34.22 & $46.61^{* * *}$ & 64.63 & 41.95 & $22.67^{* * *}$ & $16.19^{* * *}$ & $-7.74^{* *}$ \\
& $(4.30)$ & $(2.43)$ & $(5.35)$ & $(2.04)$ & $(2.99)$ & $(4.15)$ & $(4.19)$ & $(3.81)$ \\
Finalizers & 82.85 & 37.58 & $45.27^{* * *}$ & 66.93 & 46.75 & $20.18^{* * *}$ & $16.92^{* * *}$ & $-9.18^{* *}$ \\
& $(4.41)$ & $(2.77)$ & $(5.83)$ & $(2.13)$ & $(3.42)$ & $(4.59)$ & $(4.34)$ & $(4.35)$ \\
\hline \hline
\end{tabular}

Notes: $t$-test of difference in means in all cases. ${ }^{* *}$ significant at $1 \%,{ }^{* *}$ significant at $5 \%,{ }^{*}$ significant at $10 \%$.

Table 5: The effect of unemployment benefit institutions on the productivity of workers

\begin{tabular}{|c|c|c|c|c|c|c|}
\hline \multirow{3}{*}{$\begin{array}{l} \\
\text { Dependent Variable: } \\
\text { Sample: }\end{array}$} & \multicolumn{4}{|c|}{$\begin{array}{l}\text { Ordinary Least Squares } \\
\text { Productivity }\end{array}$} & \multirow{2}{*}{\multicolumn{2}{|c|}{ Always Employed }} \\
\hline & \multicolumn{2}{|c|}{$\begin{array}{r}\text { Proauctivity } \\
\text { All }\end{array}$} & \multicolumn{2}{|c|}{ Returners } & & \\
\hline & $(1)$ & $(2)$ & $(3)$ & $(4)$ & $(5)$ & $(6)$ \\
\hline Rosario & $\begin{array}{c}-7.90 \\
(5.10)\end{array}$ & $\begin{array}{c}-4.24 \\
(3.15)\end{array}$ & $\begin{array}{c}-14.48^{*} \\
(7.92)\end{array}$ & $\begin{array}{l}-10.80 \\
(7.63)\end{array}$ & $\begin{array}{l}-6.00 \\
(10.09)\end{array}$ & $\begin{array}{l}-4.92 \\
(8.88)\end{array}$ \\
\hline$U B I$ & $\begin{array}{c}22.52^{* * *} \\
(3.70)\end{array}$ & $\begin{array}{c}19.56^{* * *} \\
(3.82)\end{array}$ & $\begin{array}{c}0.58 \\
(7.98)\end{array}$ & $\begin{array}{c}3.17 \\
(9.02)\end{array}$ & $\begin{array}{c}30.68^{* * *} \\
(9.23)\end{array}$ & $\begin{array}{c}27.10^{* *} \\
(9.75)\end{array}$ \\
\hline Rosario $\times U B I$ & $\begin{array}{c}24.09^{* * *} \\
(6.61)\end{array}$ & $\begin{array}{c}23.39^{* * *} \\
(4.98)\end{array}$ & $\begin{array}{l}17.64^{*} \\
(9.50)\end{array}$ & $\begin{array}{l}16.80^{*} \\
(9.39)\end{array}$ & $\begin{array}{c}29.30^{* *} \\
(12.51)\end{array}$ & $\begin{array}{l}30.48^{* *} \\
(10.72)\end{array}$ \\
\hline Constant & $\begin{array}{c}42.11^{* * *} \\
(1.38)\end{array}$ & $\begin{array}{c}25.84^{* * *} \\
(4.94)\end{array}$ & $\begin{array}{c}36.23^{* * *} \\
(6.75)\end{array}$ & $\begin{array}{c}47.69^{* * *} \\
(15.64)\end{array}$ & $\begin{array}{c}59.36^{* * *} \\
(6.50)\end{array}$ & $\begin{array}{l}22.91^{*} \\
(11.31)\end{array}$ \\
\hline Individual controls & & $\checkmark$ & & $\checkmark$ & & $\checkmark$ \\
\hline Observations & 1,242 & 1,242 & 133 & 133 & 602 & 602 \\
\hline R-squared & 0.09 & 0.29 & 0.04 & 0.12 & 0.11 & 0.28 \\
\hline
\end{tabular}


Table 6: The effect of unemployment benefit institutions on the productivity of workers: Finalizers sample

\begin{tabular}{|c|c|c|c|c|c|c|}
\hline & & Ordinary & _east Squa & & & \\
\hline Dependent Variable: & Productix & & & & & \\
\hline Sample: & & & Retı & rners & Always & mployed \\
\hline & $(1)$ & $(2)$ & (3) & (4) & $(5)$ & $(6)$ \\
\hline Rosario & $-9.18^{*}$ & -5.51 & $-15.36^{*}$ & -11.73 & -6.00 & -4.72 \\
\hline & $(5.20)$ & $(3.91)$ & $(8.60)$ & $(7.97)$ & $(10.09)$ & $(8.88)$ \\
\hline$U B I$ & $20.18^{* * *}$ & $19.91^{* * *}$ & 0.17 & 2.22 & $30.68^{* * *}$ & $27.10^{* *}$ \\
\hline & $(4.26)$ & $(4.54)$ & $(7.94)$ & $(8.89)$ & $(9.23)$ & $(9.75)$ \\
\hline Rosario $\times U B I$ & $25.10^{* * *}$ & $25.16^{* * *}$ & 17.00 & $16.53^{\dagger}$ & $29.30 * *$ & $30.48^{* *}$ \\
\hline & $(7.03)$ & $(5.66)$ & $(10.05)$ & $(9.67)$ & $(12.51)$ & $(10.72)$ \\
\hline Constant & $46.75^{* * *}$ & $21.12^{* *}$ & $36.23^{* * *}$ & $44.96^{* * *}$ & $59.36^{* * *}$ & $22.91^{*}$ \\
\hline & $(1.67)$ & $(7.37)$ & $(6.75)$ & $(10.50)$ & $(6.50)$ & (11.31) \\
\hline Individual controls & & $\checkmark$ & & $\checkmark$ & & $\checkmark$ \\
\hline Observations & 1,134 & 1,134 & 129 & 129 & 602 & 602 \\
\hline R-squared & 0.08 & 0.26 & 0.04 & 0.11 & 0.11 & 0.28 \\
\hline
\end{tabular}

Table 7: Differences in the change of self-esteem across universities and treatments

\begin{tabular}{|c|c|c|c|c|c|c|c|c|}
\hline & \multicolumn{3}{|c|}{ Within U. Rosario } & \multicolumn{3}{|c|}{ Within U. Andes } & \multicolumn{2}{|c|}{ Across universities } \\
\hline & $\begin{array}{c}\text { Welfare } \\
(1)\end{array}$ & $\begin{array}{c}\text { Control } \\
(2)\end{array}$ & (1)vs.(2) & $\begin{array}{c}\text { Workfare } \\
(3)\end{array}$ & $\begin{array}{c}\text { Control } \\
(4)\end{array}$ & (3)vs.(4) & $\begin{array}{c}\text { UBI } \\
\text { (1)vs.(3) }\end{array}$ & $\begin{array}{c}\text { Control } \\
\text { (2)vs.(4) }\end{array}$ \\
\hline \multicolumn{9}{|l|}{ Panel A: All sample } \\
\hline Unemployed $^{a}$ & $\begin{array}{l}-2.50 \\
(1.22)\end{array}$ & $\begin{array}{l}-0.50 \\
(2.40)\end{array}$ & $U=-0.93$ & $\begin{array}{l}-0.67 \\
(0.80)\end{array}$ & $\begin{array}{l}-1.17 \\
(0.91)\end{array}$ & $U=0.44$ & $U=1.40$ & $U=-0.76$ \\
\hline Employed $^{b}$ & $\begin{array}{l}-0.47 \\
(0.44)\end{array}$ & $\begin{array}{c}0.27 \\
(0.87)\end{array}$ & $U=-0.29$ & $\begin{array}{l}-0.43 \\
(0.35)\end{array}$ & $\begin{array}{l}-0.36 \\
(0.62)\end{array}$ & $U=0.08$ & $U=0.11$ & $U=-0.34$ \\
\hline Unemp. vs. Emp. & $U=-1.88^{*}$ & $U=0.07$ & & $U=-0.56$ & $U=-0.92$ & & & \\
\hline \multicolumn{9}{|l|}{ Panel B: Finalizers } \\
\hline Unemployed $^{a}$ & $\begin{array}{l}-3.33 \\
(1.00)\end{array}$ & $\begin{array}{c}-0.5 \\
(2.40)\end{array}$ & $U=-1.33$ & $\begin{array}{l}-1.25 \\
(0.73)\end{array}$ & $\begin{array}{l}-1.00 \\
(3.00)\end{array}$ & $U=-0.07$ & $U=1.60$ & $U=-0.24$ \\
\hline Employed $^{b}$ & $\begin{array}{r}-0.47 \\
0.47\end{array}$ & $\begin{array}{c}0.27 \\
(0.87)\end{array}$ & $U=-0.29$ & $\begin{array}{l}-0.43 \\
(0.35)\end{array}$ & $\begin{array}{l}-0.50 \\
(0.67)\end{array}$ & $U=0.34$ & $U=0.11$ & $U=-0.62$ \\
\hline Unemp. vs. Emp. & $U=-2.49^{* *}$ & $U=0.07$ & & $U=-1.16$ & $U=-0.22$ & & & \\
\hline
\end{tabular}


Table 8: Differences in Job Satisfaction across universities and treatments

\begin{tabular}{|c|c|c|c|c|c|c|c|c|}
\hline & \multicolumn{3}{|c|}{ Within U. Rosario } & \multicolumn{3}{|c|}{ Within U. Andes } & \multicolumn{2}{|c|}{ Across universities } \\
\hline & $\begin{array}{l}\text { Welfare } \\
\text { (1) }\end{array}$ & $\begin{array}{l}\text { Control } \\
(2)\end{array}$ & (1)vs.(2) & $\begin{array}{l}\text { Workfare } \\
\text { (3) }\end{array}$ & $\begin{array}{c}\text { Control } \\
\text { (4) }\end{array}$ & (3)vs.(4) & $\begin{array}{c}\text { UBI } \\
\text { (1)vs.(3) }\end{array}$ & $\begin{array}{l}\text { Control } \\
\text { (2)vs.(4) }\end{array}$ \\
\hline \multicolumn{9}{|l|}{ Panel A: All sample } \\
\hline Employed on day 1 & $\begin{array}{l}24.19 \\
(0.46)\end{array}$ & $\begin{array}{l}24.20 \\
(0.63)\end{array}$ & $\begin{array}{l}-0.01 \\
(0.77)\end{array}$ & $\begin{array}{l}23.85 \\
(0.33)\end{array}$ & $\begin{array}{l}24.13 \\
(0.51)\end{array}$ & $\begin{array}{l}-0.28 \\
(0.65)\end{array}$ & $\begin{array}{l}-0.34 \\
(0.60)\end{array}$ & $\begin{array}{l}-0.07 \\
(0.82)\end{array}$ \\
\hline Employed on day 8 & $\begin{array}{l}23.46 \\
(0.55)\end{array}$ & $\begin{array}{l}23.50 \\
(0.62)\end{array}$ & $\begin{array}{l}-0.04 \\
(0.85)\end{array}$ & $\begin{array}{l}23.17 \\
(0.34)\end{array}$ & $\begin{array}{l}22.82 \\
(0.58)\end{array}$ & $\begin{array}{c}0.35 \\
(0.81)\end{array}$ & $\begin{array}{l}-0.29 \\
(0.63)\end{array}$ & $\begin{array}{l}-0.68 \\
(0.87)\end{array}$ \\
\hline \multicolumn{9}{|c|}{ Panel B: Always employed } \\
\hline $\begin{array}{l}\text { Always employed }^{a} \\
\text { (day 1) }\end{array}$ & $\begin{array}{l}23.71 \\
(0.86)\end{array}$ & $\begin{array}{l}22.44 \\
(1.60)\end{array}$ & $U=0.41$ & $\begin{array}{l}23.90 \\
(0.61)\end{array}$ & $\begin{array}{l}24.10 \\
(1.30)\end{array}$ & $U=0.04$ & $U=0.82$ & $U=0.49$ \\
\hline $\begin{array}{l}\text { Always employed }{ }^{a} \\
\text { (day 8) }\end{array}$ & $\begin{array}{l}23.53 \\
(0.77)\end{array}$ & $\begin{array}{l}22.73 \\
(1.09)\end{array}$ & $U=0.59$ & $\begin{array}{l}23.10 \\
(0.46)\end{array}$ & $\begin{array}{l}24.14 \\
(0.83)\end{array}$ & $U=-0.11$ & $U=-0.44$ & $U=1.20$ \\
\hline
\end{tabular}


Table 9: Effect of Welfare and the change in self-esteem in the probability of applying for vacancies: UBI sample

\begin{tabular}{|c|c|c|c|c|}
\hline Dependent Variable: $A p$ & $\begin{array}{l}\text { Ordinary I } \\
\text { plication d } \\
\text { (1) }\end{array}$ & $\begin{array}{l}\text { east Squal } \\
\text { mmy } \\
\quad(2)\end{array}$ & $(3)$ & (4) \\
\hline Panel A: Day 7 & & & & \\
\hline Welfare & $\begin{array}{c}-0.296^{* *} \\
(0.111)\end{array}$ & $\begin{array}{c}-0.376^{* *} \\
(0.142)\end{array}$ & $\begin{array}{c}-0.298^{* *} \\
(0.108)\end{array}$ & $\begin{array}{c}-0.361^{* *} \\
(0.145)\end{array}$ \\
\hline$\Delta$ Self-esteem & & & $\begin{array}{l}-0.0145^{*} \\
(0.00717)\end{array}$ & $\begin{array}{c}-0.0106 \\
(0.00774)\end{array}$ \\
\hline Welfare $\times \Delta$ Self-esteem & & & $\begin{array}{c}0.0658^{* * *} \\
(0.0188)\end{array}$ & $\begin{array}{c}0.0616^{* * *} \\
(0.0195)\end{array}$ \\
\hline Constant & $\begin{array}{c}0.563^{* * *} \\
(0.0482)\end{array}$ & $\begin{array}{c}0.717^{* *} \\
(0.250)\end{array}$ & $\begin{array}{c}0.566^{* * *} \\
(0.0470)\end{array}$ & $\begin{array}{c}0.703^{* *} \\
(0.237)\end{array}$ \\
\hline Observations & 94 & 94 & 94 & 94 \\
\hline R-squared & 0.076 & 0.107 & 0.129 & 0.155 \\
\hline Panel B: Day 8 & & & & \\
\hline Welfare & $\begin{array}{c}-0.0593 \\
(0.0539)\end{array}$ & $\begin{array}{c}-0.0399 \\
(0.0838)\end{array}$ & $\begin{array}{l}-0.0333 \\
(0.0637)\end{array}$ & $\begin{array}{r}-0.0226 \\
(0.108)\end{array}$ \\
\hline$\Delta$ Self-esteem & & & $\begin{array}{c}0.0455^{* * * *} \\
(0.0134)\end{array}$ & $\begin{array}{c}0.0447^{* *} \\
(0.0149)\end{array}$ \\
\hline Welfare $\times \Delta$ Self-esteem & & & $\begin{array}{c}0.00258 \\
(0.0263)\end{array}$ & $\begin{array}{c}0.00756 \\
(0.0306)\end{array}$ \\
\hline Constant & $\begin{array}{c}0.521^{* * *} \\
(0.0478)\end{array}$ & $\begin{array}{c}0.544 \\
(0.421)\end{array}$ & $\begin{array}{c}0.515^{* * *} \\
(0.0520)\end{array}$ & $\begin{array}{c}0.590 \\
(0.407)\end{array}$ \\
\hline Observations & 74 & 74 & 74 & 74 \\
\hline $\mathrm{R}$-squared & 0.003 & 0.009 & 0.111 & 0.120 \\
\hline Individual controls & & $\checkmark$ & & $\checkmark$ \\
\hline
\end{tabular}




\section{Figures}

Figure 1: Daily average productivity across UBI treatments and controls

Figure 1a: Daily average productivity by university (Control stage)

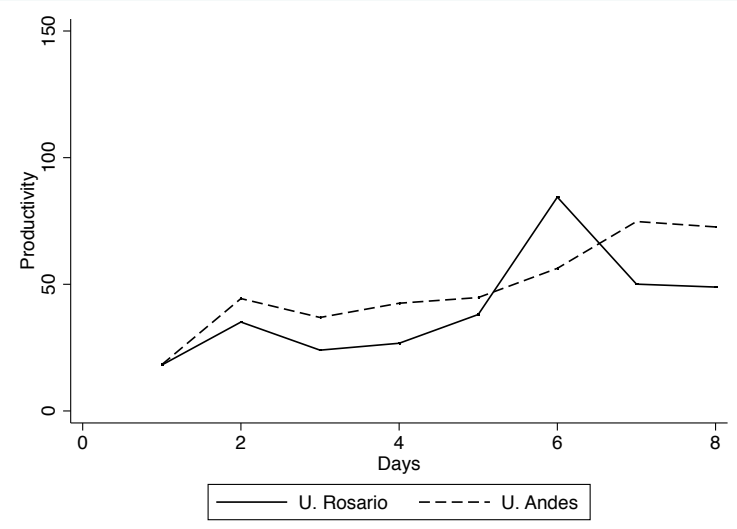

Figure 1b: Daily average productivity by university (UBI stage)

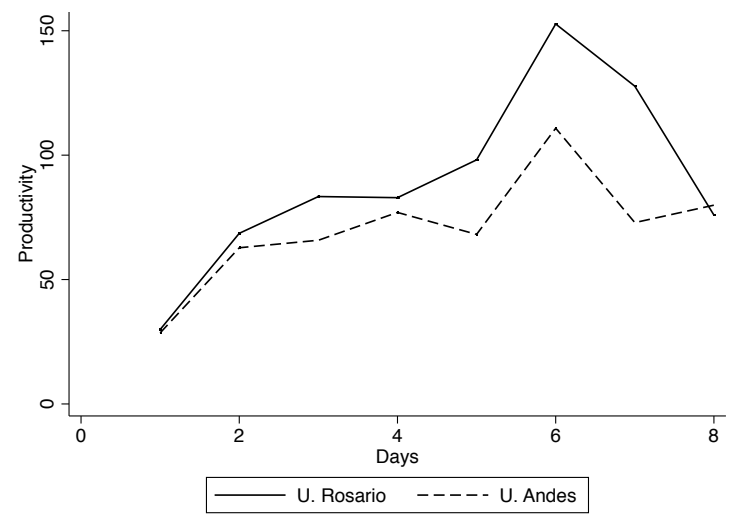

Figure 2: Daily average productivity of the always employed across UBI treatments

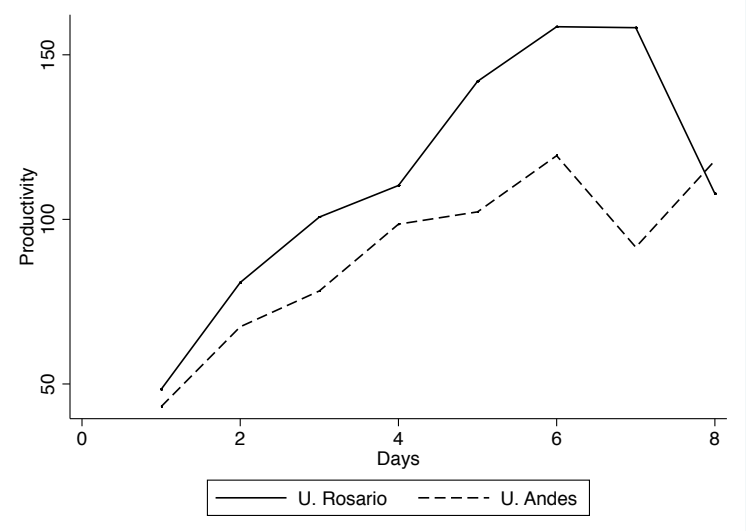




\section{Appendix}

\section{A Experimental procedures}

This appendix describes the recruitment process, the characteristics of the task, the productivity measure and the sequence of the experiment in further detail. A copy of the instructions on how to codify is available upon request to the authors.

\section{A.1 Recruitment}

We recruited students from University of Rosario and University of Los Andes, to work as research assistants. We sent an e-mail to all social sciences students announcing the opening of temporal positions to work with the Political Studies Research Group. ${ }^{45}$ Applicants had to be willing to work one and a half hours, two days a week for a month. They could choose to work Mondays and Wednesdays or Tuesdays and Thursdays, in the mornings or in the afternoons. The job announcement also stated that the number of vacancies per day would vary and that their final payment would depend on their work performance and on the labor demand per day. Given this, applicants were told to expect a final payment between US $\$ 32$ and US $\$ 90 .{ }^{46}$ The announcement also made clear that availability during the whole month period of the job was a necessary condition to be eligible. The interested candidates had to fill in a pre-formatted CV online, where they had to select the time-slots in which they were available to work. We gathered socio-demographic information such us age, gender, residential address (from which we inferred the socioeconomic stratum), GPA, current job, etc. Among all subjects available, we randomly selected and invited to the induction day approximately 100 subjects per treatment/stage. For each recruited subject, we created a non-photo badge with an ID and an e-mail account using that ID as user name and password. ${ }^{47}$ Subjects were told that we would use that e-mail account to communicate with them exclusively. ${ }^{48}$

\section{A.2 Job Description and Productivity Measurement}

As already mentioned, the job consisted in coding news about electoral practices of local politicians from the online archives of the two most popular Colombian newspapers, El Tiempo and El Espectador. The resulting dataset was used by Fergusson et al. (2013), who needed a candidate-level dataset on media exposure to look at the electoral consequences of the media exposing Congress candidates as having ties with illegal armed groups before the elections relative to exposing them after the elections.

\footnotetext{
${ }^{45}$ This group was created in order to preserve the identity of the researchers involved in the project. These researchers were never present in any of the sessions taking place in the universities to which they are affiliated to. We did so to separate the employer-employee relationship from an eventual professor-student one. Moreover, participants were told that the Political Studies Research Group was the employment agency hired by the real users of the dataset.

${ }^{46}$ For a participant who would never lose his job and hence work for a maximum of 12 hours (1.5 hours per shift $\times$ two shifts per week $\times$ four weeks) the corresponding expected final payment was between 2 and 6 times the hourly minimum wage. The incentive for taking up the job was then relatively large.

${ }^{47}$ Subjects were allowed to change the password to protect their privacy.

${ }^{48}$ We chose this procedure in order to provide anonymity especially for the unemployed who choose to stay on the unemployment benefit. We wanted to avoid the unemployed to feel any pressure to eventually apply for a new vacancy.
} 
Every working day, each coder was assigned a random list of politicians. The worker had to search online for all news mentioning the names of the politicians in his list. For each news found, he had to code information on a pre-formatted excel file. Every news coded was a new row in the file. Coders had to follow a rigorous protocol which explained step by step the search criteria as well as the type of information they had to record and how to do so. At the end of each session, they had to save their excel files with all the entries they recorded and label the file with their unique ID number and the day of work. In this way, we were able to identify uniquely the output of each coder in each working day.

Each working day lasted ninety minutes in total. Seventy minutes were used for coding and the rest of the time was used to save the file, send it to us by e-mail (from the work account we specially created for each of them) and filling in some questionnaires.

Coders' daily productivity was measured by the number of news correctly coded per day. The quality of their work was controlled by our research assistants and the workers knew this. ${ }^{49}$ After controlling for quality, the assistants would record the true productivity of each coder and create a productivity ranking of coders per group and day. These rankings were used to determine who would become unemployed (respectively re-employed), in case of negative (respectively positive) shocks. Importantly, coders did not have access to these rankings until the last day of work.

\section{A.3 Groups and Place of Work}

Coders were assigned to eighteen groups, according to their availability of time and their university. Subjects who indicated availability in more than one slot were randomly allocated to one of these slots. Once subjects were assigned to a group they were not allowed to change it during the entire period of the project. The distribution of groups was balanced across days, time of the day and newspaper to code. Half of the groups were allocated to Mondays and Wednesdays and half to Tuesdays and Thursdays. Within each day, half of the groups were in the morning and half in the afternoon. The average number of subjects in the first day of work per group was around 17, ranging from a minimum of 11 subjects to a maximum of 23. To avoid spillover and contagion between treated and control groups within each university, we implemented the UBIs interventions (i.e. Welfare and Workfare) and the intervention without UBI (i.e. Control) with a one-year difference. See Table A.1 for a detailed description of the eighteen groups.

Each group was randomly assigned to a distinct computer room. All computer rooms had at least 25 PCs or laptops and internet connection. Each session was supervised by two research assistants randomly allocated across groups. The research assistants would make sure that the session ran smoothly. They would set the computers up, record attendance, answer questions about coding, administer questionnaires, etc.

\footnotetext{
${ }^{49}$ On the induction day, coders were informed that the quality of their work was going to be monitored. In principle, coders had incentives to cheat by adding fake entries into their files. To avoid this, we assigned a team of six research assistants to control the quality of the entries. Every afternoon after the working day, our assistants would randomly take at least $15 \%$ of the news coded by each coder, and control their quality following a common evaluation protocol. They would check, for example, if the entry came from real news or was invented, if the data imputed was consistent with the information in the news, etc.
} 


\section{A.4 Sequence of the experiment}

\section{A.4.1 Induction day}

The first day was an induction day with the purpose of providing a detailed explanation of the particularities of the working scheme. Each subject received $75 \%$ of the salary of a standard working session as a show-up compensation. During the induction, subjects were reminded that their final remuneration would depend on their performance as coders, with the minimum being US\$ 32 and the maximum US\$ 90 (2 and 6 times the hourly minimum wage respectively for the maximum number of hours that they could work). They also received a detailed explanation on the way their payments were going to be computed, a description of the particularities of the job as well as the instructions on how to perform the task of coding. In addition, we told them that other researchers were interested in collecting additional data, so as part of the work activities, they would be asked to answer a set of questionnaires. ${ }^{50}$ At the end of the induction day, those subjects who accepted the terms and conditions of the job signed an informed consent and completed the first questionnaire. ${ }^{51}$

\section{A.4.2 Unemployment and Reemployment}

At the beginning of every working day, two assistants would receive the subjects, check their coder's ID and inform them about their condition as employed or unemployed for that day. The assistants would also make sure that every session consisted of 70 minutes of coding work.

We created involuntary unemployment (shortage of vacancies) in all days except for the first and last days, when we had full employment. Unemployment increased in the second and sixth day, and decreased (i.e. vacancies were opened) during the rest of the project. Table 1 shows the unemployment rate for each working day.

On the days in which there was a negative shock (i.e. an increase in the unemployment rate), the coders ranked last according to their productivity in the previous day became unemployed. Unemployed subjects were informed via e-mail of the number of job openings for the following working day. If they wanted to be considered for the new positions, they had to reply to that email. Vacancies were filled in according to applicants' productivity on their last day employed. We informed subjects their (new) condition on the following working day.

In order to be considered as part of the labor force, all subjects had to attend their working session on time, even those who were unemployed. If failed to do so (without any justified cause, such as illness), they were considered to have withdrawn from the project.

\section{A.5 Remuneration scheme}

The remuneration per 90 minutes of work was the market for research assistants in the universities where the intervention took place. We paid subjects COP\$14,250 ( $\approx$ US\$ 8). ${ }^{52}$ This salary was over four times the minimum wage in Colombia for such working shift.

\footnotetext{
${ }^{50}$ Subjects were informed that their answers to these questionnaires were going to be treated anonymously and would only be used for academic purposes.

${ }^{51}$ Only one subject out of the three hundred and nighty six who came to the induction day, did not sign the informed consent. This was the only person who decided not to take the job.

${ }^{52}$ At the time of the experiment, the average hourly salary of a research assistant was $\operatorname{COP} \$ 10,300(\approx$ $\mathrm{US} \$ 4.6)$.
} 
In addition, there was a bonus of $\operatorname{COP} \$ 40,000(\approx \mathrm{US} \$ 22)$, payable at the end of the experiment, for the subject in each group who correctly coded the highest number of news in a session.

The maximum possible remuneration was US $\$ 90$, earned by subjects who came to the induction day (US\$ 6), were employed during the eight working days (US\$ $8 \times 8$ days $=$ US\$ 64) and won the bonus for best coder of his/her group (US\$20). The minimum possible remuneration of someone who participated in the project over the whole period was US\$ 32 if the person was assigned to a treatment with an UBI, and US\$ 14 is he/she was assigned to the Control. To receive the minimum amount, the coder had to come to the induction day (US\$ 6) and worked the first day of work (US\$ 8), but remained unemployed and active since the first day of unemployment. If the coder was assigned to an UBI, then he/she would receive additional US\$ 18 (a US $\$ 3$ unemployment compensation $\times 6$ days).

In order to minimize attrition, we paid the last day of the project. Additionally, subjects who withdraw from the project without a justified reason were entitled to request only half of the money earned by the last day they showed up to work.

\section{A.6 Interventions}

As mentioned, we implemented three different experimental interventions. The Control treatment, without any UBI, and two treatments designed to mimic the two main existing UBIs (Welfare and Workfare).

The amount of the unemployment benefit was identical in the two UBI treatments and equivalent to a third of the daily shift salary of the employed. This is of course an abstraction of the real world UBIs, in which unemployment compensations vary, even within countries, according to several characteristics of the unemployed like the spell of unemployment. While we do not think that abstracting from this variation is relevant for our experiment, we did make an effort to to replicate other features of the actual implementation of UBIs. For instance, when applying for the benefit in reality, unemployed individuals have to fulfill some requirements, including signing up, filling in paperwork, and showing up regularly at some administrative office (usually to fill in additional paperwork). We had a similar procedure in our two treatments: The unemployed who wanted to receive the benefit had to show up every working day at the time and place of work. If assigned to Welfare the unemployed could leave immediately after filling in some short questionnaires and receiving the compensation. ${ }^{53}$ If assigned to Workfare, the unemployed could choose whether to complete the ancillary task and get the compensation or to leave without getting paid. ${ }^{54}$ In any case the unemployed had to show and sign an attendance sheet. Failing to do so would be equivalent to quit the job altogether and stop being considered part of the labor force (and not being able to re-apply for a position when new vacants were opened).

For comparability, unemployed coders in the Control treatment were also required to show up every working day at the time and place of work if they wanted to be considered

\footnotetext{
${ }^{53}$ We used the questionnaires to measure various psychological traits that we use when testing the mechanisms behind the main result.

${ }^{54}$ The task, which lasted 30 minutes, was to place letters in envelopes and paste on them randomly assigned (real) postal addresses. We manipulated the content of the letter in two sub-treatments. A Charity subtreatment used letters that asked for donations to a social NGO. A Placebo sub-treatment used letters to publicize the business of a local private firm. While the existence of these sub-treatments within Workfare does not affect the incentives exploited for this paper, these data will be used in subsequent companion papers.
} 
part of the labor force. Of course, they were invited to leave immediately after filling some short questionnaires.

Table A.1: Description of groups

\begin{tabular}{clllc}
\hline \hline Group & University & Newspaper & Treatment & Coders day1 \\
\hline 1 & U. Rosario & El Tiempo & Welfare & 16 \\
2 & U. Rosario & El Espectador & Welfare & 18 \\
3 & U. Rosario & El Espectador & Welfare & 14 \\
4 & U. Rosario & El Tiempo & Welfare & 11 \\
5 & U. Andes & El Tiempo & Workfare & 20 \\
6 & U. Andes & El Espectador & Workfare & 19 \\
7 & U. Andes & El Tiempo & Workfare & 23 \\
8 & U. Andes & El Espectador & Workfare & 22 \\
9 & U. Andes & El Tiempo & Workfare & 14 \\
10 & U. Andes & El Espectador & Workfare & 13 \\
11 & U. Andes & El Tiempo & Workfare & 18 \\
12 & U. Andes & El Espectador & Workfare & 18 \\
13 & U. Rosario & El Tiempo & Control & 20 \\
14 & U. Rosario & El Tiempo & Control & 15 \\
15 & U. Rosario & El Espectador & Control & 21 \\
16 & U. Andes & El Tiempo & Control & 13 \\
17 & U. Andes & El Tiempo & Control & 22 \\
18 & U. Andes & El Espectador & Control & 13 \\
\hline \hline
\end{tabular}

